\title{
Aggregate volatility expectations and threshold CAPM
}

\author{
Yakup Eser Arısoy $^{\mathrm{a}, *}$, Aslıhan Altay-Salih ${ }^{\mathrm{b}, 1}$, \\ Levent Akdeniz ${ }^{\mathrm{b}, 2}$ \\ a Université Paris-Dauphine, DRM Finance, 75775 Paris Cedex 16, France \\ ${ }^{\mathrm{b}}$ Bilkent University Faculty of Business Administration, 06533 Ankara, Turkey
}

\section{A R T I C L E I N F O}

\section{Article history:}

Received 9 March 2015

Received in revised form 16 September

2015

Accepted 21 September 2015

Available online 9 October 2015

\section{JEL classification:}

C13

G12

\section{Keywords:}

Aggregate volatility

Threshold regression

Conditional CAPM

Range

VIX

\begin{abstract}
A B S T R A C T
We propose a volatility-based capital asset pricing model (V-CAPM) in which asset betas change discretely with respect to changes in investors' expectations regarding near-term aggregate volatility. Using a novel measure to proxy uncertainty about expected changes in aggregate volatility, i.e. monthly range of the VIX index (RVIX), we find that portfolio betas change significantly when uncertainty about aggregate volatility expectations is beyond a certain threshold level. Due to changes in their market betas, small and value stocks are perceived as riskier than their big and growth counterparts in bad times, when uncertainty about aggregate volatility expectations is high. The proposed model yields a positive and significant market risk premium during periods when investors do not expect significant uncertainty in near-term aggregate volatility. Our findings support a volatility-based time-varying risk explanation.
\end{abstract}

(c) 2015 Elsevier Inc. All rights reserved.

\footnotetext{
* Corresponding author. Tel.: +33 144054360 .

E-mail addresses: eser.arisoy@dauphine.fr (Y.E. Arısoy), asalih@bilkent.edu.tr (A. Altay-Salih), akdeniz@bilkent.edu.tr (L. Akdeniz).

1 Tel: +90 3122902047.

2 Tel: +903122902202.
} 


\section{Introduction}

The capital asset pricing model (CAPM) assumes that a firm's riskiness, which is captured by its beta, is constant through time. However, changes in business conditions, technology, and taste might induce shifts in the investment opportunity set and investors' associated risk-return tradeoffs (Jagannathan \& Wang, 1996). Many studies model the variation in betas using continuous approximation and the theoretical framework of the conditional CAPM ${ }^{1}$. Yet, despite a strong theory and considerable evidence on time variation in betas, there is no consensus on how this variation should be modelled.

In this paper, we model asset betas neither as static nor as a continuous approximation implied by conditional models, instead we assume that asset betas change discretely in time ${ }^{2}$. Our approach follows the spirit of regime-switching models, which have been extensively used in modelling financial time-series ${ }^{3}$. More particularly, we posit that investors re-assess firms' systematic risk with respect to expected changes in aggregate risk conditions based on their expectations regarding uncertainty about future aggregate volatility. There are several reasons why we assume betas should change with respect to uncertainty about aggregate volatility expectations. First, it is well documented that both equity and aggregate volatility is time-varying ${ }^{4}$. Therefore, an asset pricing model that incorporates time-variation in aggregate volatility would naturally imply that asset betas also change accordingly ${ }^{5,6}$. Second, time-varying risk literature suggests that stocks have different exposures to market risk during recessions and expansions (Lettau \& Ludvigson, 2001; Petkova \& Zhang, 2005). Given the fact that change in aggregate volatility is tightly linked to business cycles, our model is able to capture this link by conditioning changes in asset betas on changes in aggregate volatility expectations ${ }^{7}$. Driven by the fact that option-implied volatility measures are good forecasts of future volatility, we condition time variation in betas based on an optionimplied measure, which summarizes investors' expectations with respect to changes in near-term aggregate volatility ${ }^{8}$. Rather than using macro variables as in previous studies, our approach contributes to the literature by proposing a novel conditioning variable, which has a forward-looking

\footnotetext{
1 See Harvey (1989), Ferson and Harvey (1991, 1993, 1999), Ferson and Korajczyk (1995), Jagannathan and Wang (1996), and Petkova and Zhang (2005).

2 The intuition behind discrete changes in betas with respect to two different regimes similar to downside-upside beta approach in Ang, Cheng, and Xing (2006a) who show that asset betas change during downside and upside markets and downside risk is priced. Methodologically, our approach is also related to Markov chain regime switching models as in Guidolin and Timmermann (2008) and Chen, Gerlach, and Lin (2011), and optimal changepoint approach as in Bollen and Whaley (2009), and Patten and Ramadorai (2013).

3 See Hamilton (1989), Hamilton and Lin (1996), and Ang and Bekaert (2002) for details and applications of regime-switching models in different settings.

${ }^{4}$ For theoretical background and empirical evidence on stochastic volatility of equity and stock market returns, see Engle and Bollerslev (1986), French, Schwert, and Stambaugh (1987), Schwert (1989), Engle and Ng (1993), Canina and Figlewski (1993), Duffee (1995), Braun, Nelson, and Sunier (1995), Andersen (1996), Bollerslev and Mikkelsen (1999) and Bekaert and Wu (2000).

${ }^{5}$ Given the definition of beta, i.e., $\beta_{i}=\left(\operatorname{Cov}\left(r_{i}, r_{m}\right) / \operatorname{Var}\left(r_{m}\right)\right)$, any uncertainty in investors' aggregate volatility expectations (i.e. the denominator) is expected to affect returns in the cross-section through betas on the market portfolio. Hence, our approach is different from Ang et al. (2006a), Ang, Hodrick, Xing, and Zhang (2006b) who condition expected returns directly on aggregate volatility and who model aggregate volatility as a separate risk factor. Our approach is also different from Wang and Ma (2014) who examine the effect of excess volatility at the individual stock level. We investigate the implications of uncertainty about aggregate volatility on betas and on the cross-section of expected returns.

${ }^{6}$ Pollet and Wilson (2010) show that increases in market volatility can be due to either increases in average volatilities or average correlations, or both. Furthermore, Buraschi, Porchia, and Trojani (2010) and Buraschi, Trojani, and Vedolin (2014) show that investors have hedging demands against both stochastic aggregate volatility risk and stochastic correlation risk. In their model, both risk factors stem as a result of uncertainty (disagreement in beliefs across agents) in the economy. We do not take a direct stand on the correlation structure in this paper. However, because our measure RVIX essentially captures uncertainty in expected volatility of the market portfolio, it is closely linked to both sources of risk.

7 See Hsu and $\mathrm{Li}$ (2009) who document counter-cyclicality of volatility across different asset classes.

${ }^{8}$ For the predictive ability of option-implied volatility measures ranging from intra-day forecasts to one-year ahead forecasts, and in different markets such as foreign exchange, stock, bond, and option markets, see Poon and Granger (2005), Taylor, Yadav, and Zhang (2010), Busch, Christensen, and Nielsen (2011), Han and Park (2013) and Bianconi, MacLachlan, and Sammon (2015).
} 
feature by construction and which models time variation in an asset's riskiness in a parsimonious way $^{9,10}$.

In particular, we propose a volatility-based threshold CAPM (V-CAPM) where asset betas change with respect to investors' assessment of aggregate risk conditions, proxied by uncertainty about market's expectations regarding changes in aggregate volatility. The contribution of the proposed V-CAPM is fourfold. First, we propose a novel measure to proxy expected changes in aggregate risk conditions, i.e. range of the VIX index (RVIX) ${ }^{11}$. VIX is inherently a forward-looking volatility measure and it reveals important information about investors' expectations of near term volatility in the market ${ }^{12}$. Defined as the difference between the maximum and minimum level of the VIX index, RVIX essentially captures expected changes in near-term aggregate volatility, or put differently the degree of uncertainty in future aggregate volatility. In a recent paper, Baltussen, Bekkum, and Grient (2015) show that the volatility of volatility (vol-of-vol) is an important factor in the cross-section of stock returns. Using the volatility of option-implied volatility as a measure of uncertainty about volatility, they document that stocks with high vol-of-vol underperform stocks with low vol-of-vol. The authors argue that the volatility of option-implied volatility is an intuitive measure, which is tightly related to the literature that models uncertainty as second-order beliefs. In a similar vein, RVIX can be interpreted as a measure that captures uncertainty regarding future aggregate volatility. Hence, if investors hold second order beliefs and care about this uncertainty, then stocks or portfolios with different sensitivities to changes in uncertainty could have different risk-return dynamics, which could also imply different market risk premium dynamics at times of increased uncertainty about expected aggregate volatility.

Second contribution is our approach to modelling time variation in betas. In standard conditional CAPM setting, betas practically change at each point in time, however this approach might have a tendency to overstate the time variation in betas and result in estimates that are highly volatile. Our setting differs from the standard conditional CAPM models by allowing betas to change only when the degree of uncertainty about expected aggregate volatility moves beyond a certain threshold level, admitting a discrete variation in betas in two distinct regimes. Third, our model implicitly allows for time variation in aggregate volatility which is not possible in the static CAPM setting. By endogenously incorporating changes in investors' expectations about aggregate volatility in a dynamic way, we allow betas to capture potential shifts in the investment opportunity set linked to expected changes in aggregate risk conditions ${ }^{13}$. Our fourth contribution is econometric. We formally test the hypothesis on the existence of a relation between betas and uncertainty about aggregate volatility using Hansen's (2000) threshold regression methodology, which is intuitive and fully supported by the econometric theory ${ }^{14}$. The proposed model is rich in its predictions and offers

\footnotetext{
${ }^{9}$ Among the most widely used macro conditioning variables in the literature are the dividend yield (Fama \& French, 1988), default spread (Keim \& Stambaugh, 1986), term spread (Campbell, 1987), short term treasury bill rate (Fama \& Schwert, 1977) and log consumption-wealth ratio (Lettau \& Ludvigson, 2001).

10 Our study is also related to the recent strand of literature showing that the difference in option-implied volatility measures has significant explanatory power in the cross-section of stock returns. Among them are studies by Bali and Hovakimian (2009), Bollerslev, Tauchen, and Zhou (2009), Cremers and Weinbaum (2010) and Atilgan, Bali, and Demirtas (2015).

11 We examine whether using other conditioning variables documented in the literature (such as one month T-bill rate, aggregate dividend yield, inflation rate, term spread and credit spread) result in significant regime changes in portfolio betas as implied by the threshold CAPM model. None of the examined variables yield significant regime shifts in portfolio betas as strong as RVIX.

12 Often referred to as the "fearör "market sentimentïndex, VIX estimates near-term (roughly next 30-day) expected volatility by weighted-averaging the prices of puts and calls written on the S\&P 500 index over a range of strike prices.

13 We also investigate whether the documented regime changes in betas with respect to uncertainty about aggregate volatility expectations is linked to downside risk as in Ang et al. (2006a) and Bali, Demirtas, and Levy (2009). Using upside and downside betas of Ang et al. (2006a), we do not find a strong correlation between high uncertainty vs. downside betas and low uncertainty vs. upside betas. Furthermore, dividing the sample period into months that correspond to high vs. low uncertainty about aggregate volatility and months that correspond to upside and downside markets, we find major differences between the corresponding time periods.

14 See Hansen (2000) for a detailed explanation of the threshold estimation methodology.
} 
a volatility-based explanation to some of the empirical asset pricing anomalies documented in the literature.

Using RVIX as proxy for uncertainty about aggregate volatility expectations, and portfolios sorted with respect to market capitalizations and book-to-market ratios as test assets, our results can be summarized as follows ${ }^{15}$. First, using the modified sup LM test suggested by Hansen (1996), we document significant time variation in betas. 15 out of 22 test portfolios have significant bootstrap $p$-values at 5\% level ${ }^{16}$. The evidence confirms the existence of aggregate volatility related changes in betas of most portfolios, most particularly for the extreme size and book-to-market portfolios as well as SMB and HML portfolios. The initial results support the hypothesis that asset betas change discretely in time and uncertainty about aggregate volatility expectations is a key determinant of investors' assessment about an asset's systematic risk.

Next, we test whether different size and book-to-market portfolios have different beta sensitivities with respect to investors' expectations about uncertainty of aggregate volatility and risk conditions. The threshold estimates suggest that investors overwhelmingly update their beta risk assessments when monthly range of the VIX index is beyond 9.33 points ${ }^{17}$. What makes the results further remarkable is the direction of this update. Looking at the changes in portfolio betas, one can see that stocks in small (and value) portfolios have consistently higher betas at times when uncertainty about expected aggregate volatility is high (i.e. when RVIX in a given month is above the threshold level). On the contrary, the portfolio of largest market capitalization stocks (and the growth portfolio) exhibits lower betas during these uncertain times. The increase in betas is most pronounced for the smallest decile, highest book-to-market decile, SMB and HML portfolios.

French et al. (1987), and Campbell and Hentschel (1992) document that periods of high volatility usually coincide with downward market moves. Furthermore, risk-averse investors are reluctant to lose wealth in periods of high volatility because it represents a deterioration in investment opportunities, which usually coincides with periods of low consumption (recessions) ${ }^{18}$. The increase in betas of small and value portfolios implies that stocks with these characteristics are perceived to be riskier at times of increased uncertainty about expected volatility. This also holds for SMB and HML portfolios whose sensitivities to market returns become higher during those times. Investors view small and value firms riskier because their returns correlate strongly with market returns in episodes when uncertainty about expected aggregate volatility is high. On the other hand, returns on big and growth stocks correlate less with market returns during those times. Our results are consistent with those of Lettau and Ludvigson (2001) and Petkova and Zhang (2005) who find that value and small stocks correlate more with the consumption growth (market returns) during bad times relative to big and growth stocks, while the opposite holds during good times. We argue that investors view small and value stocks riskier than their big and growth counterparts because their returns are much more sensitive to market risk at times of increased uncertainty about aggregate volatility and adverse market conditions.

To test the robustness of the above results and to further examine the effect of time variation in investors' expectations of near term volatility on asset risk-return dynamics, we next calculate Jensen's alphas and Sharpe ratios of our test assets in the full sample as well as in two different regimes (i.e. high and low uncertainty about volatility) implied by the threshold level of RVIX estimated via the V-CAPM. It is well-documented that small and value stocks (and the associated SMB and HML strategies) produce significantly higher average returns than their large and growth counterparts. Looking at Jensen's alphas and betas of different size and book-to-market portfolios, we confirm the previous findings that the static CAPM is unable to offer a risk-based

\footnotetext{
15 We also use an orthogonalized version of RVIX (RVIXORTH) in order to ensure that the results are not driven by potential variables that have been documented to be important in the literature. RVIXORTH is defined as the residual term obtained from regressing RVIX on aggregate dividend yield, the default spread, the term spread, the short-term treasury bill rate, and the VIX. The results are robust to use of RVIXORTH as the conditioning variable.

169 (17) portfolios exhibit significant change in betas at $1 \%(10 \%)$ level.

17 The threshold estimates (which could practically be any positive real number) are quite stable for portfolios that exhibit significant beta changes (ranging from 6.07 to 11.10), confirming the robustness of the chosen threshold variable, RVIX.

$18 \mathrm{Hsu}$ and $\mathrm{Li}$ (2009) document that equity market volatility is higher in bear markets and recessions.
} 
explanation to SMB and HML return differentials. On the other hand, the analysis of alphas implied by the proposed V-CAPM helps us uncover an important aspect of size and value vs. growth puzzles. In particular, we document that size and value strategies yield significant and positive risk-adjusted returns during calm times when uncertainty about near-term aggregate volatility is low. On the other hand, the trade-off for size and value strategies is that they have extremely bad (significant and negative) risk-adjusted returns at times of high uncertainty about expected volatility.

Portfolio Sharpe ratios also offer a similar volatility-based time-varying risk explanation to size and value vs. growth anomalies. In periods when uncertainty about aggregate volatility is low, the strategy in the smallest (value) decile portfolios command higher reward-to-variability ratios as opposed to the biggest (growth) decile portfolios. However, in periods of high uncertainty about aggregate volatility, investors experience much worse reward-to-variability ratios for the smallest (value) decile portfolio relative to biggest (growth) decile portfolio. The results confirm our hypothesis that market's expectation of uncertainty about aggregate volatility is an important determinant of investors' assessment of risk and expected returns. Changes in betas and risk-adjusted returns during periods with different levels of uncertainty about aggregate volatility expectations contribute to our understanding of why small and value stocks on average earn higher returns than their big and growth counterparts. We show that investing in small and value stocks are risky strategies in periods when there is high uncertainty about expected aggregate volatility, and thus investors get compensated for the risk that they are taking against this uncertainty.

We finally test the pricing implications of the proposed V-CAPM by dividing the sample into periods of high and low uncertainty about expected aggregate volatility and by estimating the betas and the corresponding risk premium in the cross-section. To avoid the problem of factor structure related biases in the estimation procedure, we estimate the betas and the risk premia at the individual stock level rather than at the portfolio level. We start with examining the relationship between stocks' betas and future returns. To that end, we first estimate the beta loadings via monthly regressions using daily returns as in Ang et al. (2006a,b). Classifying betas as high uncertainty (RVIX > 9.33) vs. low uncertainty (RVIX $<9.33$ ) betas, we form decile portfolios each month by sorting individual stocks according to their betas. We then examine out-of-sample average decile returns for the following month to investigate whether stocks' beta exposures determined by uncertainty about aggregate volatility explain the cross-sectional dispersion in their next-month returns. Univariate portfolio sorts indicate that stocks in the highest uncertainty (calm) beta decile underperform (outperform) stocks in the lowest uncertainty (calm) beta decile by $0.72 \%(0.60 \%)$ per month. Furthermore, the differences in risk-adjusted returns (CAPM and FF 3-factor alphas) of portfolios with highest and lowest exposure to uncertainty betas are also negative and statistically significant. The results are robust to using value-weighted returns.

We finally estimate the corresponding risk premia for uncertainty and calm betas using the standard Fama and MacBeth (1973) cross-sectional regression methodology. Consistent with the previous studies, we document an insignificant market risk premium throughout the full sample period, confirming the inability of a static version of CAPM to explain the cross-section of stock returns. On the other hand, we document a positive and significant market risk premium during calm times when uncertainty about aggregate volatility is low. This result is robust to the inclusion of different factor exposures such as SMB beta, HML beta and MOM beta as well as various firm characteristics such as idiosyncratic volatility, size, book-to-market ratio, and firm-level momentum. On the contrary, during periods of high uncertainty about aggregate volatility, the market risk commands a significant and negative premium, however its significance disappears when different portfolio exposures and firm characteristics are included. The results imply a major improvement over pricing relative to static CAPM by re-establishing a positive market risk premium during calm periods when uncertainty about aggregate volatility is fairly low.

The remainder of the paper is organized as follows. Section 2 introduces the threshold V-CAPM and the related econometric framework. Section 3 presents data and some stylized facts. Section 4 documents empirical findings for time-series and cross-sectional tests of the proposed V-CAPM. The final section offers concluding remarks. 


\section{The threshold CAPM}

To capture the effect of uncertainty about aggregate volatility expectations on market beta, we start with the following conditional CAPM:

$$
E\left[r_{i, t+1} \mid Z_{t}\right]=\alpha_{i}+\beta_{t} E\left[r_{m, t+1} \mid Z_{t}\right]+\varepsilon_{i t+1},
$$

where $r_{i, t+1}$ is the excess return on asset $i, r_{m, t+1}$ is the excess return on the market portfolio and $E$ is the expectation operator. $\beta_{t}$ captures time-variation in market betas, and $Z_{t}$ is the conditioning information on investors' assessment of near-term aggregate volatility risk. Using monthly range of the VIX index as a proxy for investors' information set for expected changes in aggregate volatility, we model time-variation in betas as in Ferson and Harvey $(1999)^{19}$ :

$$
\beta_{t}=\beta_{1} 1_{\left\{Z_{t} \leq \lambda\right\}}+\beta_{2} 1_{\left\{Z_{t}>\lambda\right\}},
$$

where $1_{\{\}}$is the indicator function and $\lambda$ is the threshold parameter for aggregate volatility. Combining Eqs. (1) and (2), we have the following threshold volatility CAPM:

$$
r_{i, t+1}=\left(\alpha_{1} 1_{\left\{Z_{t} \leq \lambda\right\}}+\alpha_{2} 1_{\left\{Z_{t}>\lambda\right\}}\right)+\left(\beta_{1} 1_{\left\{Z_{t} \leq \lambda\right\}}+\beta_{2} 1_{\left\{Z_{t}>\lambda\right\}}\right) r_{m, t+1}+\varepsilon_{i, t+1},
$$

where $Z_{t}$ is the monthly range of the VIX index (RVIX) that summarizes investors' information set regarding the evolution of uncertainty about near-term aggregate volatility.

\subsection{Econometric model}

The observed sample is $\left\{r_{t+1}, r_{m, t+1}, Z_{t}\right\}, t=1, \ldots, T-1$. The random variables $r_{t}, r_{m, t}$, and $Z_{t}$ are real-valued. The threshold variable $Z_{t}$ is assumed to have a continuous distribution ${ }^{20}$. The threshold regression has the same format as in Eq. (3), which can be rewritten as

$$
r_{t+1}=\theta^{\prime} x_{t+1}+\delta^{\prime} x_{t+1}(\lambda)+e_{t+1}
$$

where $x_{t+1}=r_{m, t+1}, x_{t+1}(\lambda)=x_{t+1} 1_{\left\{z_{t} \leq \lambda\right\}}, \theta=\beta_{2}$ and $\delta=\beta_{1}-\beta_{2}$.

The above model can further be generalized to the case where only a subset of parameters switches between the regimes and to the case where some regressors only enter in one of the two regimes. Also, $\lambda$ takes values in a bounded subset of the real line, $\Gamma$. This applies to the case of our conditioning variable RVIX, which is bounded below by zero by definition. We assume $r_{m t}, Z_{t}$, and $e_{t}$ are strictly stationary ergodic and $\rho$-mixing ${ }^{21}$.

\subsection{Testing for a threshold}

We use the heteroskedasticity-consistent Lagrange Multiplier (LM) test for a threshold, as in Hansen (1996). We test for the null of $H_{0}: \delta=0$ against $H_{1}: \delta \neq 0$. If the null is rejected, this implies a significant change in betas with respect to levels above or below threshold RVIX.

For all $\lambda \in \Gamma$ we have the following LM statistics for the null of no threshold:

$$
\operatorname{LM}_{T}(\lambda)=T[R \hat{\gamma}(\lambda)]^{\prime}\left[R \hat{V}_{T}^{*}(\lambda) R^{\prime}\right]^{-1}[R \hat{\gamma}(\lambda)]
$$

\footnotetext{
19 See Section 2 for details on the construction of the conditioning variable RVIX.

20 See Hansen (2000) for detailed explanations related to the assumptions.

21 The $\rho$-mixing coefficients satisfy $\sum \rho_{m}^{1 / 2}<\infty$. The $\rho$-mixing assumption controls the degree of time series dependence and allows the processes to be autocorrelated and heteroskedastic, and is sufficiently flexible to embrace many non-linear time series processes, including threshold autoregressions.
} 
where,

$$
\begin{aligned}
& R=[0, I] \\
& \hat{\gamma}(\lambda)=\left[\hat{\theta}(\lambda)^{\prime}, \hat{\delta}(\lambda)^{\prime}\right]^{\prime}=\left[\sum_{t=1}^{T} x_{t+1}^{*}(\lambda) x_{t+1}^{*}(\lambda)^{\prime}\right]^{-1}\left[\sum_{t=1}^{T} x_{t+1}^{*}(\lambda) r_{t+1}\right] \\
& x_{t+1}^{*}(\lambda)=\left[x_{t+1}, x_{t+1}(\lambda)\right] \\
& \hat{V}_{T}^{*}(\lambda)=M_{T}(\lambda)^{-1} \tilde{V}_{T}(\lambda) M_{T}(\lambda)^{-1}, \\
& M_{T}(\lambda)=\frac{1}{T} \sum_{t=1}^{T} x_{t+1}^{*}(\lambda) x_{t+1}^{*}(\lambda)^{\prime}, \\
& \tilde{V}_{T}(\lambda)=\frac{1}{T} \sum_{t=1}^{T} x_{t+1}^{*}(\lambda) x_{t+1}^{*}(\lambda)^{\prime} \tilde{e}_{t+1}^{2},
\end{aligned}
$$

and where $\tilde{e}_{t}$ is obtained from the restricted least squares. One limitation of the LM test is the large sample limit for the sup-LM, which is not nuisance free because the threshold is not identified under the null of no-threshold effect. Because of this issue, Hansen (1996) suggests a bootstrap analog of the sup-LM test and shows that this bootstrap method yields asymptotically correct $p$-values. We use the bootstrap analog following the steps outlined in Hansen (1996) and estimate the unknown threshold parameter, $\lambda$, as in Hansen (2000).

\section{Data}

The market and stock return data is from Center for Research in Security Prices (CRSP) valueweighted market index for all NYSE, AMEX, and NASDAQ stocks. The risk-free rate is the one-month T-Bill rate obtained from Ibbotson Associates. Data on VIX and VXO is obtained from Chicago Board Options Exchange's (CBOE). The sample covers the period from January 1986 to December 2012, with a total of 324 months $^{22}$. The test portfolios consist of stocks sorted according to their market capitalizations, and book-to-market ratios. More precisely, we use 10 portfolios sorted according to their market capitalizations, 10 portfolios sorted according to their book-to-market ratios, and 2 factor portfolios $\mathrm{SMB}$ and $\mathrm{HML}^{23}$. For cross-sectional tests performed in Section 4.3, we use the CRSP universe covering all NYSE/AMEX/NASDAQ common stocks with share codes 10 and 11.

In order to proxy investors' expectations about the evolution of near-term aggregate volatility, we use the monthly range of the VIX index (RVIX). Similar to Chou (2005), we define RVIX in a given month as:

$$
\operatorname{RVIX}_{t}=\operatorname{Max}\left\{\operatorname{VIX}_{\tau}\right\}-\operatorname{Min}\left\{\operatorname{VIX}_{\tau}\right\}, \quad \tau=1,2, \ldots, T
$$

where $\tau$ denotes trading days in a given month, and $t$ denotes months. Taking the difference between the maximum and minimum level of VIX index in a given month, RVIX summarizes investors' expectations regarding changes in near-term aggregate volatility.

\footnotetext{
22 VIX data is available from January 1990 onwards. In order to have as much data as possible, we use the VXO index (which is based on S\&P 100 index options) from January 1986 to December 1989, and the VIX index from its introduction in January 1990 onwards. The results remain unaffected when we limit the sample period to 1990-2012 using the VIX index only, or omitting VIX and using VXO throughout the 1986-2012 period.

${ }^{23}$ SMB (Small Minus Big) is the average return on the three small portfolios minus the average return on the three big portfolios, and HML (High Minus Low) is the average return on the two value portfolios minus the average return on the two growth portfolios.
} 
Range based volatility measures have gained recent interest, and they fare quite well in predicting future volatility ${ }^{24}$. To the best of our knowledge, this is the first study to propose a range based measure of the VIX index ${ }^{25}$. We further tested a battery of volatility measures ranging from statistical and historical measures of volatility such as standard deviation of returns, squared returns, GARCH based volatility estimates to forward-looking measures of volatility such as change in the VIX index and S\&P 500 straddle returns ${ }^{26}$. The proposed RVIX together with S\&P 500 straddle returns are the most successful in capturing time-variation in betas.

We argue that the success of RVIX in detecting changes in betas is due to its ability to characterize uncertainty about future aggregate volatility much better than alternative measures. By using a measure which essentially captures volatility of option-implied aggregate volatility, we have the advantage of first identifying investors' expectations about the evolution of near-term aggregate volatility (VIX), and second measuring the degree of uncertainty in expected aggregate volatility captured by the range of the this forward-looking option-implied aggregate volatility measure (RVIX). Aggregate volatility risk has been documented to be an important factor that determines investors' risk-return tradeoff and time-variation in investment opportunity $\operatorname{set}^{27}$. Because RVIX is essentially a proxy for the degree of uncertainty regarding aggregate volatility expectations, we expect RVIX to be a strong conditioning variable that captures uncertainty in investors' information set regarding aggregate volatility risk, and hence to have implications regarding asset pricing, portfolio allocation, and stock return predictability as an important conditioning variable.

We further test whether the chosen conditioning variable RVIX is correlated with other business cycle measures documented in the literature ${ }^{28}$. Towards that end, we are particularly interested in the dividend yield (DIV) of the S\&P 500 index, the default spread (DEF) which the spread between BAA and AAA rated corporate bond yields, the term spread (TERM) which is the spread between 10-year, 1-year U.S. government bond yields and the short-term treasury bill rate (TB) and the VIX index, all of which have been documented as strong predictors of business cycles and hence the conditional CAPM information set ${ }^{29}$. To check whether our results are not affected from a potential correlation with the business cycle variables documented in the literature, we create an orthogonalized measure of RVIX (RVIXORTH), which is defined as the residual term from the following regression:

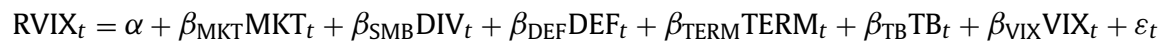

Table 1 reports the summary statistics of RVIX, the market portfolio, as well as the orthogonalized version of RVIX (RVIXORTH), and macro variables used in the analysis. Looking at the mean (6.66), median (4.98), the minimum (0.92) and the maximum (129.04) of the RVIX, one can say that VIX index (expectations of near-term market volatility) and its range (expected changes in near-term aggregate volatility) are quite stable and do not move significantly in most of the months during our sample period. Without much surprise, the maximum level of RVIX was recorded in October 1987, where the VXO index skyrocketed from its minimum value on 3rd October 1987 of 21.15 points to its historical maximum of 150.19 points on black Monday. Finally, similar to the negative correlation

\footnotetext{
24 See Alizadeh, Brandt, and Diebold (2002), Chou (2005), Brandt and Jones (2006), Chou and Liu (2010), Harris, Stoja, and Yilmaz (2011) and Bannouh, Martens, and van Dijk (2013) for articles that motivate the use of range based volatility measures in different settings.

${ }^{25}$ Previous studies such as Garman and Klass (1980) and Parkinson (1980) as well as many others use the logarithmic transformation of the stock price as a measure of stock volatility. Although the asymptotic properties and forecasting power of price-based range measures has been extensively documented, as far as the authors are aware of, this is the first paper that applies the concept of range to implied volatility. To have a better understanding of the properties of RVIX, we check the predictive ability of RVIX to forecast realized variance (VAR) as defined in Welch and Goyal (2008). The pairwise correlation between RVIX in month $t$-and VAR in month $t+1$ is 0.27 .

${ }^{26}$ The reader is referred to Section 4.4 for a detailed discussion of results.

27 See Campbell (1993), Chen (2002), Ang et al. (2006a,b) and Barinov (2012) for papers that document pricing of aggregate volatility risk.

${ }^{28}$ See Ang and Chen (2002) and Ang and Bekaert (2002) for studies that document increase in correlations during recessions.

29 Dividend yield data is from Robert Shiller's website (http://www.econ.yale.edu/ shiller/data.htm), government and corporate bond yields are from St. Louis Fed website (https://research.stlouisfed.org/fred2/), and short-term Treasury bill rates are from Ken French's data library, (http://mba.tuck.dartmouth.edu/pages/faculty/ken.french/data_library.html).
} 
Table 1

Descriptive statistics.

\begin{tabular}{|c|c|c|c|c|c|c|c|}
\hline \multicolumn{8}{|c|}{ Panel A: summary statistics } \\
\hline & MKT & RVIX & RVIXORTH & TERM & DEF & DIV & TB \\
\hline Mean & 0.89 & 6.66 & 0 & 1.43 & 1.00 & 0.02 & 0.31 \\
\hline Median & 1.49 & 4.98 & 0.04 & 1.47 & 0.91 & 0.02 & 0.37 \\
\hline Maximum & 12.88 & 129.04 & 84.04 & 3.40 & 3.38 & 0.39 & 0.79 \\
\hline Minimum & -22.64 & 0.92 & -16.67 & -0.41 & 0.55 & 0.01 & 0 \\
\hline Std.Dev & 4.61 & 8.36 & 6.11 & 1.07 & 0.40 & 0.01 & 0.20 \\
\hline Skewness & -0.89 & 10.25 & 8.60 & 0.10 & 2.87 & 0.34 & -0.11 \\
\hline Kurtosis & 5.48 & 144.02 & 121.09 & 1.82 & 14.94 & 1.85 & 2.08 \\
\hline \multicolumn{8}{|c|}{ Panel B: correlations } \\
\hline MKT & 1 & & & & & & \\
\hline RVIX & -0.41 & 1 & & & & & \\
\hline RVIXORTH & 0 & 0.73 & 1 & & & & \\
\hline TERM & -0.04 & 0.09 & 0 & 1 & & & \\
\hline DEF & -0.08 & 0.28 & 0 & 0.29 & 1 & & \\
\hline DIV & 0.02 & 0.08 & 0 & 0.13 & 0.32 & 1 & \\
\hline TB & 0.04 & -0.05 & 0 & -0.71 & -0.34 & 0.36 & 1 \\
\hline
\end{tabular}

This table reports the descriptive statistics for monthly returns on the market portfolio (MKT), and monthly range of the VIX index (RVIX), as well as orthogonalized measure of RVIX (RVIXORTH), and 4 business cycle related measures. The market portfolio is the CRSP value-weighted index for all NYSE, AMEX, and NASDAQ stocks. RVIX is the difference between maximum and minimum level of VIX in a given month, i.e. $R V I X_{t}=\operatorname{Max}\left\{\mathrm{VIX}_{\tau}\right\}-\operatorname{Min}\left\{\mathrm{VIX}_{\tau}\right\}, \tau=1,2, \ldots, T$, where $\tau$ denotes trading days in a given month, and $t$ denotes months. DIV is the dividend yield of the S\&P 500 index. DEF is defined as the spread between BAA and AAA rated corporate bond yield and TERM is the spread between 10-year and 1-year U.S. government bond yields. TB is the one-month Treasury Bill rate. RVIXORTH is the residual term from the following regression:

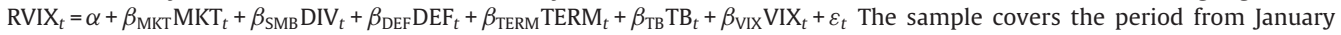
1986 to December 2012 (324 months). For the period covering January 1986 to December 1989, VIX is replaced by VXO which is based on S\&P 100 index options. All return figures are in percentages.

documented in previous studies between the VIX index and market returns, the correlation between RVIX and the market is -0.41 .

\subsection{Stylized facts}

This section documents some stylized facts about the chosen threshold parameter, market returns, and the empirically documented size and value vs. growth anomalies.

First, looking at Fig. 1, one can see that the proposed conditioning variable RVIX indeed tracks significant negative market moves. Given the empirical evidence that negative market moves are most associated with increases in aggregate volatility, our novel measure RVIX is essentially capable of providing a relationship between the evolution of near-term market volatility and downward market moves.

Next, we conduct a simple exercise to examine returns on different size and book-to-market portfolios in different volatility regimes in more detail. Using threshold estimates of the RVIX index, we divide the sample into two regimes, where regime 1 (2) represents calm (uncertain) months in which RVIX is below (above) the estimated threshold level of the associated portfolio. This way of decomposing returns into calm and uncertain months gives us interesting insights regarding investor' expectations about uncertainty in near-term aggregate volatility and portfolio return dynamics. For example, looking at columns 5 and 10 of Table 2, one can see that asset classes, regardless of their portfolio characteristics, lose much more when market volatility is expected to be highly volatile. This is in line with Hsu and Li (2009) who document that volatile periods coincide with bear markets. On the other hand, columns 2, 3, 7 and 8 document the typical size and value vs. growth anomalies. More particularly, static CAPM fails to offer a clear and linear relationship between betas and portfolio returns, i.e. high (low) returns are not always justified by high (low) CAPM betas. However, looking at columns $4,5,9$, and 10 of Table 2, one can gain interesting insights. For example, in calm months (when RVIX 


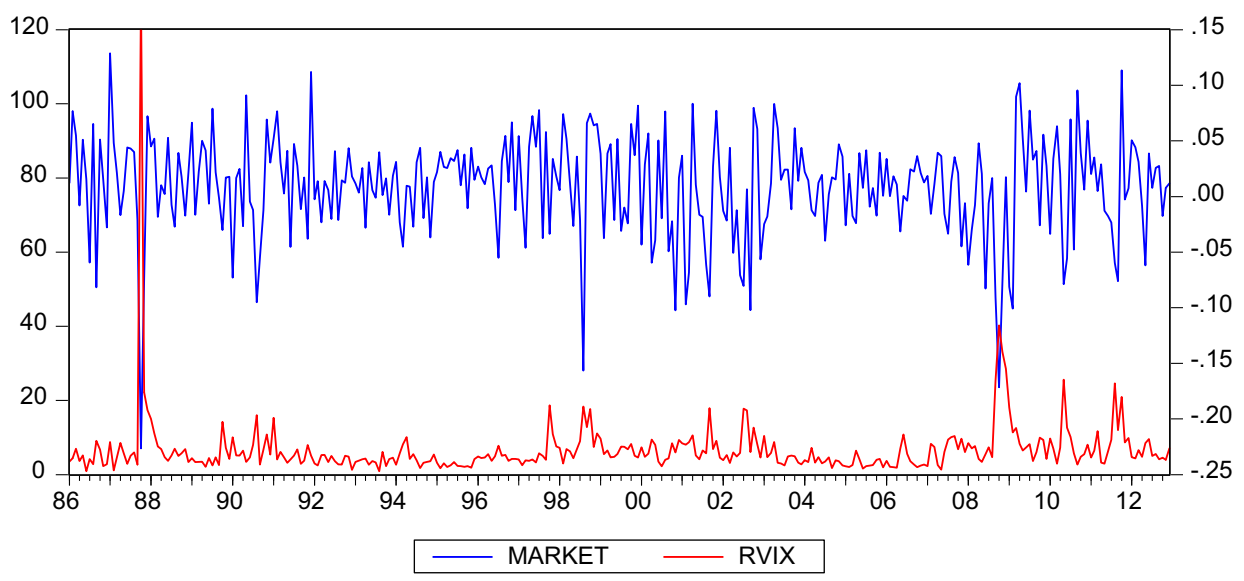

Fig. 1. Time-series of RVIX and market returns.

Table 2

Stylized facts about portfolio returns.

\begin{tabular}{llllllllll}
\hline Size & Beta & $\begin{array}{l}\text { Full } \\
\text { sample }\end{array}$ & $\begin{array}{l}\text { Regime1 } \\
\text { (Calm) }\end{array}$ & $\begin{array}{l}\text { Regime2 } \\
\text { (Volatile) }\end{array}$ & B/M & Beta & $\begin{array}{l}\text { Full } \\
\text { sample }\end{array}$ & $\begin{array}{l}\text { Regime1 } \\
\text { (Calm) }\end{array}$ & $\begin{array}{l}\text { Regime2 } \\
\text { (Volatile) }\end{array}$ \\
\hline Small & 1.0163 & 0.0097 & 0.0176 & -0.0365 & High & 1.0557 & 0.0115 & 0.0187 & -0.0298 \\
Decile2 & 1.1604 & 0.0096 & 0.0170 & -0.0330 & Decile2 & 0.9864 & 0.0107 & 0.0160 & -0.0203 \\
Decile3 & 1.1434 & 0.0104 & 0.0173 & -0.0297 & Decile3 & 0.9716 & 0.0091 & 0.0149 & -0.0239 \\
Decile4 & 1.1262 & 0.0094 & 0.0158 & -0.0271 & Decile4 & 0.9512 & 0.0102 & 0.0147 & -0.0156 \\
Decile5 & 1.1380 & 0.0104 & 0.0164 & -0.0240 & Decile5 & 0.9467 & 0.0090 & 0.0135 & -0.0167 \\
Decile6 & 1.0713 & 0.0104 & 0.0157 & -0.0213 & Decile6 & 0.9029 & 0.0096 & 0.0143 & -0.0179 \\
Decile7 & 1.0673 & 0.0108 & 0.0164 & -0.0205 & Decile7 & 0.8487 & 0.0098 & 0.0153 & -0.0221 \\
Decile8 & 1.0795 & 0.0103 & 0.0156 & -0.0203 & Decile8 & 0.8445 & 0.0102 & 0.0141 & -0.0124 \\
Decile9 & 1.0101 & 0.0101 & 0.0148 & -0.0170 & Decile9 & 0.9228 & 0.0093 & 0.0129 & -0.0109 \\
Big & 0.9449 & 0.0087 & 0.0118 & -0.0096 & Low & 1.0501 & 0.0090 & 0.0116 & -0.0066 \\
SMB & 0.0716 & 0.0010 & 0.0058 & -0.0269 & HML & 0.0059 & 0.0026 & 0.0071 & -0.0231 \\
Market & & 0.0089 & 0.0129 & -0.0143 & Market & & 0.0089 & 0.0128 & -0.0143 \\
\hline
\end{tabular}

This table presents the returns on several portfolios that have been used as test assets in this study and the market portfolio during the full sample period from January 1986 through December 2012 (324 months) and two different volatility regimes. Size represents portfolios which contain stocks sorted with respect to their market capitalizations. B/M represents portfolios which contain stocks sorted with respect to their book-to-market ratios. SMB is a portfolio that is long in stocks in the smallest decile and short in stocks in the biggest decile. HML is a portfolio that is long in stocks which are in the highest B/M decile and short in stocks which are in the lowest $\mathrm{B} / \mathrm{M}$ decile.

is below the estimated threshold), one can see almost a monotonous decrease in returns going from small and value portfolios through big and growth portfolios. The opposite is true for episodes when uncertainty about aggregate volatility is high, when small and value portfolios become the worst performers. Despite their higher average returns relative to big and growth portfolios, small and value stock portfolios become the worst performers at times of high uncertainty about expected aggregate volatility when the market is expected to do badly ${ }^{30}$. On the other hand, by losing less than the market portfolio, big and growth portfolios can be seen as relatively safer asset classes during uncertain periods about aggregate volatility and market conditions.

The preliminary findings informally confirm our hypotheses that size and book-to-market portfolios have different sensitivities to market risk during periods of different expectations regarding the

\footnotetext{
30 This also holds for the zero-cost SMB and HML portfolios, which earn on average 58 and 71 basis points per month during calm market conditions, but which become extremely risky strategies and lose 269 and 231 basis points, respectively, during high expected volatility periods.
} 
evolution of aggregate volatility. Thus, we posit that an asset pricing model that correctly takes into account this volatility-based time variation in risk and returns is expected to do better in pricing and in explaining size and value vs. growth anomalies.

\section{Tests of V-CAPM}

We begin by examining whether there are statistically significant regime shifts in betas due to changes in investors' expectations regarding uncertainty about aggregate volatility and market conditions. Our conditioning variable is range of the VIX index and Table 3 reports the associated bootstrap $p$-values for the sup-LM test. The null hypothesis is that there is no significant regime shift in portfolio betas. According to bootstrap $p$-values presented in Table 3, there are significant regime changes in betas of most portfolios. For portfolios sorted with respect to market capitalizations, eight out of ten experience significant changes in their betas between uncertain and calm periods about expected aggregate volatility. For portfolios sorted with respect to book-to-market ratios, the evidence indicates a regime shift in betas of seven out of ten portfolios. SMB and HML portfolios also exhibit significant regime shifts in betas. The results are also robust to using the orthogonalized version of RVIX (RVIXORTH). Taking into account that the threshold parameter RVIX captures investors' expectations about uncertainty in near-term volatility, uncertainty about the evolution of aggregate volatility seems to be an important determinant of their assessment of aggregate risk conditions and an asset's sensitivity to overall market risk. The results, if persistent, offer new evidence and an alternative explanation to the empirically observed size and value vs. growth anomalies.

The conditional CAPM models may have a tendency to overstate the time variation, and as a result, continuous approximations of CAPM produce highly volatile beta estimates. This is further confirmed with the evidence reported in Braun et al. (1995), who use a bivariate EGARCH model to estimate conditional betas and document weak evidence of time variation. On the other hand, our threshold methodology using RVIX as a conditioning variable suggests that portfolio betas are stable during different expected volatility regimes, however investors update their beta estimates when their expectations regarding the uncertainty about near-term volatility change considerably.

Table 3

Bootstrap $p$-values for 10 size and $\mathrm{B} / \mathrm{M}$ portfolios.

\begin{tabular}{llllll}
\hline Size & RVIX & RVIXORTH & B/M & RVIX & RVIXORTH \\
\hline Small & $0.000^{* * *}$ & $0.000^{* * *}$ & High & $0.012^{* *}$ & $0.000^{* * *}$ \\
Decile2 & $0.000^{* * *}$ & $0.024^{* * *}$ & Decile2 & $0.009^{* * *}$ & $0.001^{* * *}$ \\
Decile3 & $0.000^{* * *}$ & $0.035^{* *}$ & Decile3 & $0.013^{* *}$ & $0.000^{* * *}$ \\
Decile4 & $0.015^{* *}$ & $0.042^{* *}$ & Decile4 & 0.144 & 0.148 \\
Decile5 & $0.025^{* * *}$ & $0.051^{*}$ & Decile5 & $0.029^{* *}$ & $0.009^{* *}$ \\
Decile6 & 0.140 & $0.044^{* *}$ & Decile6 & $0.067^{*}$ & $0.022^{* *}$ \\
Decile7 & $0.016^{* *}$ & $0.003^{* * *}$ & Decile7 & $0.008^{* * *}$ & $0.030^{* *}$ \\
Decile8 & 0.144 & $0.009^{* * *}$ & Decile8 & 0.435 & 0.642 \\
Decile9 & $0.056^{* * *}$ & $0.018^{* *}$ & Decile9 & 0.219 & 0.167 \\
Big & $0.008^{* * *}$ & $0.007^{* * *}$ & Low & $0.000^{* * *}$ & $0.000^{* * *}$ \\
SMB & $0.009^{* * *}$ & $0.058^{* *}$ & HML & $0.001^{* * *}$ & $0.000^{* * *}$ \\
\hline
\end{tabular}

This table reports the bootstrap p-values of the modified sup-LM test suggested by Hansen (1996). We test the null hypothesis of no significant regime shifts in portfolio betas due to changes in the level of uncertainty regarding aggregate volatility expectations, captured by RVIX, as well as an orthogonalized measure of RVIX (RVIXORTH). RVIXORTH is the residual term from the following regression:

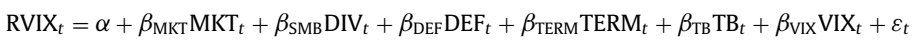

Size represents portfolios which contain stocks sorted with respect to their market capitalizations, and B/M represents portfolios which contain stocks sorted with respect to their book-to-market ratios, respectively. The sample period covers January 1986 to December 2012 (324 months).

, ,**** Denote significance levels at $10 \%, 5 \%$, and $1 \%$, respectively. 
Table 4

Threshold estimates for 10 size and 10 book-to-market portfolios.

\begin{tabular}{|c|c|c|c|c|}
\hline \multicolumn{5}{|c|}{ Panel A: 10 size portfolios } \\
\hline & CAPM beta & Beta for regime 1 & Beta for regime 2 & Threshold estimate \\
\hline Small & 1.0163 & 0.9093 & 1.2350 & 8.80 \\
\hline Decile2 & 1.1604 & 1.0772 & 1.1662 & 8.42 \\
\hline Decile3 & 1.1434 & 1.0453 & 1.2060 & 9.33 \\
\hline Decile4 & 1.1262 & 1.0401 & 1.1874 & 9.33 \\
\hline Decile5 & 1.1380 & 1.0684 & 1.1884 & 9.33 \\
\hline Decile6 & 1.0713 & 1.0330 & 1.2516 & 17.69 \\
\hline Decile7 & 1.0673 & 1.0109 & 1.1067 & 9.33 \\
\hline Decile8 & 1.0795 & 1.0478 & 1.0919 & 6.07 \\
\hline Decile9 & 1.0101 & 0.9723 & 1.0190 & 9.33 \\
\hline Big & 0.9449 & 0.9762 & 0.9223 & 9.33 \\
\hline SMB & 0.0716 & -0.0616 & 0.3026 & 9.33 \\
\hline \multicolumn{5}{|c|}{ Panel B: $10 \mathrm{~B} / \mathrm{M}$ portfolios } \\
\hline & CAPM beta & Beta for regime 1 & Beta for regime 2 & Threshold estimate \\
\hline High & 1.0557 & 0.9776 & 1.0831 & 9.58 \\
\hline Decile2 & 0.9864 & 0.9357 & 1.0513 & 9.58 \\
\hline Decile3 & 0.9716 & 0.9247 & 1.0606 & 9.58 \\
\hline Decile4 & 0.9512 & 0.9038 & 1.0399 & 9.58 \\
\hline Decile5 & 0.9467 & 0.8687 & 1.0648 & 11.10 \\
\hline Decile6 & 0.9029 & 0.8308 & 1.0127 & 11.10 \\
\hline Decile7 & 0.8487 & 0.7983 & 0.8906 & 10.92 \\
\hline Decile8 & 0.8445 & 0.7425 & 0.9266 & 15.00 \\
\hline Decile9 & 0.9228 & 0.8373 & 0.9944 & 10.78 \\
\hline Low & 1.0501 & 1.1249 & 0.9892 & 9.33 \\
\hline HML & 0.0059 & -0.1514 & 0.0930 & 9.33 \\
\hline
\end{tabular}

This table reports the unconditional CAPM betas, the threshold beta estimates with respect to low and high volatility regimes, and their associated threshold volatility estimates, proxied by S\&P 500 at-the-money straddle returns. Panels A and B present results for portfolios sorted with respect to market capitalizations, and book-to-market ratios, respectively. SMB is a portfolio that is long in stocks in the smallest decile and short in stocks in the biggest decile. HML is a portfolio that is long in stocks which are in the highest $\mathrm{B} / \mathrm{M}$ decile and short in stocks which are in the lowest $\mathrm{B} / \mathrm{M}$ decile. The sample covers the period from January 1986 to December 2012 (324 months). Regime 1 (2) corresponds to low (high) uncertainty about volatility regimes where monthly RVIX is lower (higher) than the estimated threshold level.

\subsection{The relation between aggregate volatility expectations and beta}

Having detected significant regime shifts in betas for most of the portfolios, we proceed to test the magnitude of this change, and estimate asset betas and their associated threshold parameters during uncertain and calm periods about expected aggregate volatility. Table 4 reports the static CAPM betas, betas estimated via the V-CAPM in calm (regime 1) and high uncertainty (regime 2) regimes, together with the threshold estimate of RVIX, which determines the change in uncertainty about aggregate volatility expectations, above (or below) which investors re-assess a stock's riskiness.

Before going into detailed analysis of portfolio betas Table 4, looking at the last column of Panel A, one can see that the estimated threshold level of RVIX is very stable across size portfolios, which is estimated at 9.33 in 7 of the 11 cases $^{31}$. Given that RVIX can take on any positive real number, this consistent level of the threshold estimate affirms the robustness of the threshold estimation procedure, the proposed model, and the chosen threshold parameter, RVIX. We argue that the stability of RVIX across portfolios signals to the degree of uncertainty that the market views as critical regarding aggregate volatility expectations. When range of VIX index in a given month is below 9.33, the uncertainty

\footnotetext{
31 The threshold levels of 17.69 and 6.07 for deciles 6 and 8 might seem as big deviations from 9.33 at first sight, however, note that these are the two portfolios where the sup-LM test was unable to detect significant regime changes. This is also the case for decile 8 of book-to-market sorted portfolios, which is detected as a portfolio with insignificant regime shift and has a relatively high threshold estimate of 15.00 .
} 
in the market is tolerable and betas remain unaffected. However, when RVIX is more than 9.33, this indicates that uncertainty in the market regarding the evolution of expected aggregate volatility has increased, and hence investors update their information set and risk-return dynamics with respect to this information, which is also reflected in betas accordingly.

Next, a detailed analysis of columns 3 and 4 of Panel A reveals important insights about how the riskiness of different size sorted portfolios changes from one volatility regime to the other. We note significant changes in beta risk of size sorted portfolios. In particular, betas of small stock portfolios increase considerably at times of high uncertainty about expected aggregate volatility. Furthermore, it is only the biggest decile portfolio, which exhibits a decrease in its beta during high uncertainty episodes.

The above findings imply that investors re-assess the riskiness of size sorted portfolios when range of the VIX index is above (or below) the threshold level of 9.33. For example, when aggregate volatility is expected to be volatile significantly (i.e. when RVIX is above the threshold), investors re-estimate the beta for the smallest decile portfolio, and update it from 0.91 in calm periods to 1.24 in uncertain periods. Similarly, the riskiness of the biggest decile portfolio changes when the RVIX is above (or below) the threshold level of 9.33. More specifically, the beta for the biggest portfolio drops from 0.98 in calm volatility periods to 0.92 in uncertain periods. Furthermore, the beta differential between the smallest and biggest portfolios (SMB) increases from -0.06 in the low expected volatility regime to 0.30 in the high uncertainty regime about expected aggregate volatility.

Our findings imply that the sensitivity of an asset's return with respect to the level of uncertainty regarding expected aggregate volatility is an important determinant of an asset's riskiness. This has clear implications on pricing and portfolio allocation. For example, by having a lower covariance with the market at times of high uncertainty about market volatility, biggest decile portfolio tends to lose less than any other size-based strategy during volatile periods. Also given that volatile episodes usually coincide with downward market moves and recessions, a strategy invested in the biggest decile portfolio appears to be relatively less risky for risk-averse investors, who are reluctant to lose wealth during those times. This implies a demand for big stocks, thus pushing their prices up and resulting in lower average returns. Similarly, the risk of small stock portfolios goes up when near-term aggregate volatility is expected to be volatile. Because uncertainty and increases in aggregate volatility are mostly associated with bad market conditions and deteriorations in investor wealth, by correlating highly with the market at times of high uncertainty about aggregate volatility, small stocks are viewed as riskier at times when extra dollar of loss is much more important.

Panel B of Table 4 offers similar results for portfolios sorted with respect to book-to-market ratios. Value portfolios have consistently higher betas at times of high uncertainty about expected volatility, whereas it is only the growth portfolio whose beta decreases during those times. The results indicate significant time variation in the risk assessments of value and growth portfolios with respect investors' expectations about uncertainty in near-term aggregate volatility. Investors view value stocks much riskier because they have a higher correlation with the market at times of high uncertainty about aggregate volatility. Similarly, a portfolio strategy in growth stocks tends to be less risky at those times. The results are in line with Lettau and Ludvigson (2001) and Petkova and Zhang (2005), who also document time variation in riskiness and expected returns of value and growth stocks, in conditional CCAPM and conditional CAPM settings, respectively.

\subsection{The relation between aggregate volatility expectations and risk-adjusted returns}

The documented evidence so far indicates that asset betas change significantly between different volatility regimes, depending on whether investors expect significant uncertainty about aggregate volatility or not. Furthermore, the proposed V-CAPM reveals a distinctive pattern regarding change of beta risk among different asset classes. More particularly, small market capitalization and high bookto-market (value) portfolios become riskier at times of high uncertainty about aggregate volatility expectations. On the other hand, big market capitalization and low book-to-market (growth) portfolios become less risky at those times. The findings of our model offer a potential remedy to the static CAPM and its failure in explaining the well documented size and value vs. growth anomalies. In order to examine the robustness of the proposed volatility-based time-varying beta risk explanation, and 
Table 5

Comparison of Jensen's alphas.

\begin{tabular}{|c|c|c|c|}
\hline \multicolumn{4}{|c|}{ Panel A: 10 Size portfolios } \\
\hline & $\alpha_{\text {CAPM }}$ & $\alpha_{\mathrm{V} \text {-CAPM, Regime } 1}$ & $\alpha_{\mathrm{V} \text {-CAPM, Regime2 }}$ \\
\hline Small & $0.0636(0.25)$ & $0.5601\left(1.98^{* *}\right)$ & $-2.1113\left(-4.47^{* * *}\right)$ \\
\hline Decile2 & $-0.0221(-0.11)$ & $0.3322(1.37)$ & $-1.5210\left(-3.50^{* * *}\right)$ \\
\hline Decile3 & $0.0680(0.41)$ & $0.3908\left(1.96^{*}\right)$ & $-1.1887\left(-2.85^{* * *}\right)$ \\
\hline Decile4 & $-0.0177(-0.12)$ & $0.2389(1.32)$ & $-0.9651\left(-2.48^{* *}\right)$ \\
\hline Decile5 & $0.1753(0.58)$ & $0.2750\left(1.80^{*}\right)$ & $-0.6550\left(-2.22^{* *}\right)$ \\
\hline Decile6 & $0.1089(0.94)$ & $0.2543(2.00)$ & $-0.4421(-1.50)$ \\
\hline Decile7 & $0.1521(1.43)$ & $0.3319\left(3.02^{* * *}\right)$ & $-0.5203\left(-1.77^{*}\right)$ \\
\hline Decile8 & $0.0938(0.92)$ & $0.2158\left(1.94^{*}\right)$ & $-0.4439\left(-1.86^{*}\right)$ \\
\hline Decile9 & $0.1147(1.49)$ & $0.1997\left(2.35^{* *}\right)$ & $-0.2266(-1.25)$ \\
\hline Big & $0.0111(0.20)$ & $-0.0792(-1.27)$ & $0.3373\left(2.37^{* *}\right)$ \\
\hline SMB & $-0.3088(-0.85)$ & $0.2543(1.33)$ & $-2.6881\left(-4.48^{* * *}\right)$ \\
\hline \multicolumn{4}{|c|}{ Panel B: 10 B/M portfolios } \\
\hline & $\alpha_{\text {CAPM }}$ & $\alpha_{\mathrm{V} \text {-CAPM, Regime } 1}$ & $\alpha_{\mathrm{V} \text {-CAPM, Regime2 }}$ \\
\hline High & $0.2306(0.94)$ & $0.5930\left(2.26^{* *}\right)$ & $-1.4147\left(-3.40^{* * *}\right)$ \\
\hline Decile2 & $0.2241(1.40)$ & $0.4556\left(2.34^{* *}\right)$ & $-0.6294\left(-2.27^{* *}\right)$ \\
\hline Decile3 & $0.1143(0.61)$ & $0.4352\left(2.29^{* *}\right)$ & $-1.1103\left(-2.54^{* *}\right)$ \\
\hline Decile4 & $0.2190(1.33)$ & $0.3595\left(1.75^{*}\right)$ & $-0.3378(-1.14)$ \\
\hline Decile5 & $0.0443(0.35)$ & $0.1756(1.16)$ & $-0.1842(-0.63)$ \\
\hline Decile6 & $0.1256(0.89)$ & $0.3015\left(1.77^{*}\right)$ & $-0.4080(-1.21)$ \\
\hline Decile7 & $0.1060(0.73)$ & $0.3309\left(1.95^{*}\right)$ & $-0.7462\left(-2.50^{* *}\right)$ \\
\hline Decile8 & $0.1566(1.58)$ & $0.1791\left(1.75^{*}\right)$ & $0.1433(0.49)$ \\
\hline Decile9 & $0.0547(0.62)$ & $0.0167(0.15)$ & $0.3516(1.61)$ \\
\hline Low & $-0.0222(-0.18)$ & $-0.2426\left(-1.88^{*}\right)$ & $0.7474\left(2.66^{* *}\right)$ \\
\hline HML & $0.0600(0.17)$ & $0.4331\left(2.53^{* *}\right)$ & $-2.4016\left(-4.10^{* * *}\right)$ \\
\hline
\end{tabular}

This table reports Jensen's alphas for the unconditional CAPM and for the threshold volatility model (V-CAPM) with respect to low and high volatility regimes. The sample covers the period from January 1986 to December 2012 (324 months). Regime 1 (2) corresponds to low (high) uncertainty about volatility regimes where monthly RVIX is lower (higher) than the estimated threshold level. The numbers in parentheses denote the associated $t$-statistics with Newey-West corrected standard errors. ${ }^{* * *}$, **, and * denote significance at $1 \%, 5 \%$, and $10 \%$ level, respectively.

to see whether investors' expectations about uncertainty in aggregate volatility has a similar timevarying effect on risk-adjusted returns, we next compare Jensen's alphas and Sharpe ratios within the full sample, and in calm and high uncertainty regimes determined by the threshold level of RVIX.

\subsubsection{Comparison of Jensen's alphas}

It is well-documented that small and value stocks on average produce significantly higher returns than their large and growth counterparts ${ }^{32}$. However, looking at Jensen's alphas and betas of different size and book-to-market portfolios in Table 5, we confirm previous studies that static CAPM is unable to offer a risk-based explanation to these abnormal returns. On the other hand, alphas implied by different volatility regimes help us uncover an important aspect of size and value vs. growth puzzles, offering a volatility-based time-varying risk explanation.

We initially document that size and value strategies pay off at times of low expected volatility yielding significant and positive risk-adjusted returns. However, the trade-off for these strategies is that they have extremely bad (significant and negative) risk-adjusted returns at times of high uncertainty about expected volatility. For example, a strategy invested in the smallest decile portfolio earns an average risk-adjusted return of 56 basis points during calm months, whereas the same strategy yields a risk-adjusted return of -211 basis points in months when uncertainty about volatility is high. Similarly, a strategy invested in the highest book-to-market (value) portfolio earns an average riskadjusted return of 59 basis points during calm months, but yields an average risk-adjusted return

\footnotetext{
32 Although excess returns on small stocks over big stocks have been disappearing during the last two decades, excess returns on value stocks over growth stocks have been significantly persistent over years.
} 
of -142 basis points in months when uncertainty about volatility is high. SMB and HML strategies also yield similar and significant risk-adjusted returns over calm and uncertainty periods. On the contrary, although strategies in biggest and lowest book-to-market (growth) portfolios disappoint their investors in calm months with average risk-adjusted returns of 8 and 24 basis points, respectively, they yield positive and significant risk-adjusted returns in months when uncertainty about volatility is high ( 24 and 75 basis points, respectively).

\subsubsection{Comparison of Sharpe ratios}

Next, we look at another popular measure of risk-adjusted return proposed by Sharpe $(1966,1975)$. Sharpe ratio is a commonly used measure to track the performance of mutual funds and it can be easily applied to measure the reward-to-variability of any investment asset or portfolio. By scaling an asset's excess return to the standard deviation of excess returns on the asset, it is an ideal way of measuring of reward-to-variability of a managed fund and the sensitivity of returns on an investment class or a trading strategy per unit of risk taken ${ }^{33}$. The measure is model free, hence it provides an indirect test for the robustness of our chosen volatility parameter RVIX, as we will compare the Sharpe ratios of test assets within the whole sample with those obtained in two different volatility regimes determined by RVIX. Analyzing reward-to-variability ratios in different volatility regimes will give us further insight about the risk-return dynamics of the test assets with respect investors' expectations regarding the uncertainty about the evolution of near-term volatility.

Looking at Panel A of Table 6, one can detect no clear pattern in Sharpe ratios of portfolios sorted with respect to market capitalizations within the full sample. One can even say that during the sample period, an investment strategy based on stocks in the smallest size decile commands a lower reward per unit of risk taken as opposed to a strategy based on stocks in the highest decile, which is not consistent with a rational risk-based explanation. On the other hand, when we decompose the sample into two volatility regimes determined by the RVIX, we see different risk-return dynamics across size sorted portfolios in different volatility regimes. In calm periods, the strategy in the smallest decile portfolio commands a higher reward-to-variability ratio compared to the biggest decile portfolio $(0.2727$ vs. 0.2250 ), however in periods when uncertainty about volatility is high, the situation is reversed, investors experience a much worse reward-to-variability ratio for the smallest decile portfolio against the biggest decile ( -0.4513 vs. -0.1727 ). This different pattern in Sharpe ratios is also consistent with our previous results documenting significant differences in betas and Jensen's alphas of those strategies and explains why investors would want to be compensated for the extra risk that they are taking by investing in small stocks.

We observe a similar pattern for the Sharpe ratios of portfolios sorted with respect to book-to market ratios. Although there is not a significant in Sharpe ratios in the full sample, we document that value portfolios command higher (lower) reward-to-variability ratios compared to growth portfolios in calm (uncertain) periods, offering a coherent volatility-based risk-return explanation to the empirically documented value vs. growth anomaly. The results confirm our hypothesis that market's expectation of uncertainty in aggregate volatility is an important determinant of investors' assessment of risk-return dynamics. Changes in betas and risk-adjusted returns help us uncover why small and value stocks on average earn higher returns than their big and growth counterparts. By conditioning asset returns using a novel forward-looking volatility measure (RVIX), which summarizes investors' expectations about the uncertainty of near-term aggregate volatility, the proposed V-CAPM offers a volatility-based time-varying risk explanation to the size and value vs. growth anomalies.

\subsection{Cross-sectional analysis}

The time-series analyses at the portfolio level in the first part indicate distinct exposure of size and book-to-market ratio sorted portfolios to uncertainty about aggregate volatility expectations, which manifests itself with significant changes in portfolio betas during low and high uncertainty

\footnotetext{
33 The excess return on the asset can be on any benchmark such as the S\&P 500 returns or the risk-free rate. As in most studies, we choose returns in excess of the risk-free rate to measure an asset's excess return
} 
Table 6

Comparison of Sharpe ratios.

\begin{tabular}{|c|c|c|c|c|c|c|}
\hline \multicolumn{7}{|c|}{ Panel A: 10 Size portfolios } \\
\hline & $S_{\text {full }}$ & $\sigma_{\text {full }}$ & $S_{\text {Regime } 1}$ & $\sigma_{\text {Regime1 }}$ & $S_{\text {Regime2 }}$ & $\sigma_{\text {Regime2 }}$ \\
\hline Small & 0.1047 & 6.1800 & 0.2727 & 5.2697 & -0.4513 & 8.6296 \\
\hline Decile2 & 0.0995 & 6.4755 & 0.2486 & 5.5158 & -0.3761 & 9.4052 \\
\hline Decile3 & 0.1197 & 6.0513 & 0.2833 & 4.9713 & -0.3423 & 9.3709 \\
\hline Decile4 & 0.1073 & 5.8601 & 0.2605 & 4.8034 & -0.3200 & 9.2201 \\
\hline Decile5 & 0.1264 & 5.7654 & 0.2774 & 4.7388 & -0.2899 & 9.1022 \\
\hline Decile6 & 0.1369 & 5.2880 & 0.2894 & 4.3103 & -0.2692 & 8.4899 \\
\hline Decile7 & 0.1475 & 5.1879 & 0.3159 & 4.1494 & -0.2799 & 8.4778 \\
\hline Decile8 & 0.1374 & 5.1926 & 0.2912 & 4.2296 & -0.2718 & 8.3341 \\
\hline Decile9 & 0.1451 & 4.7889 & 0.2965 & 3.8871 & -0.2493 & 7.7732 \\
\hline Big & 0.1238 & 4.4706 & 0.2250 & 3.8149 & -0.1727 & 6.9428 \\
\hline SMB & -0.0664 & 3.2503 & 0.0570 & 3.2547 & -0.5456 & 2.8644 \\
\hline \multicolumn{7}{|c|}{ Panel B: 10 B/M portfolios } \\
\hline & $S_{\text {full }}$ & $\sigma_{\text {full }}$ & $S_{\text {Regime1 }}$ & $\sigma_{\text {Regime1 }}$ & $S_{\text {Regime2 }}$ & $\sigma_{\text {Regime2 }}$ \\
\hline High & 0.1376 & 6.0808 & 0.3009 & 5.1259 & -0.3601 & 8.9403 \\
\hline Decile2 & 0.1548 & 4.8706 & 0.3275 & 3.9062 & -0.2871 & 7.8923 \\
\hline Decile3 & 0.1305 & 4.5919 & 0.3300 & 3.5221 & -0.3430 & 7.6930 \\
\hline Decile4 & 0.1564 & 4.5171 & 0.3034 & 3.7634 & -0.2560 & 7.0277 \\
\hline Decile5 & 0.1240 & 4.7423 & 0.2702 & 3.7813 & -0.2403 & 7.9366 \\
\hline Decile6 & 0.1389 & 4.6370 & 0.2981 & 3.7196 & -0.2668 & 7.6018 \\
\hline Decile7 & 0.1360 & 4.8830 & 0.3072 & 3.9252 & -0.3128 & 7.8432 \\
\hline Decile8 & 0.1503 & 4.6758 & 0.2802 & 3.8612 & -0.1958 & 7.5451 \\
\hline Decile9 & 0.1306 & 4.7558 & 0.2433 & 3.9492 & -0.1732 & 7.6979 \\
\hline Low & 0.1125 & 5.1623 & 0.1829 & 4.5820 & -0.1185 & 7.5777 \\
\hline HML & 0.0180 & 3.0837 & 0.0943 & 2.9435 & -0.3368 & 3.5854 \\
\hline
\end{tabular}

This table reports portfolio ex-post Sharpe ratios and standard deviations for the full sample and two subsamples representing two different volatility regimes. Regime 1 (2) corresponds to low (high) uncertainty about volatility regimes where monthly RVIX is lower (higher) than the estimated threshold level. Panels A and B presents results for portfolios sorted with respect to market capitalizations, and book-to-market ratios, respectively. SMB is a portfolio that is long in stocks in the smallest decile and short in stocks in the biggest decile. HML is a portfolio that is long in stocks which are in the highest $\mathrm{B} / \mathrm{M}$ decile and short in stocks which are in the lowest B/M decile. The sample covers the period from January 1986 to December 2012 (324 months).

periods about aggregate volatility. However, it is important to note that stocks can exhibit significant cross-sectional variation within each portfolio. Therefore even though time-series analysis at the portfolio level point towards RVIX being a potentially important conditioning variable in explaining stock returns, this explanatory power might result from stocks' other characteristics. In the next section, we examine whether cross-sectional differences in beta-return relationship are attributable to RVIX at the individual stock level, and whether betas implied by high vs. low uncertainty about aggregate volatility is a priced risk factor in the cross-section.

\subsubsection{Univariate portfolio sorts based on threshold RVIX betas}

We start with examining whether stock betas estimated via threshold level of RVIX can predict the cross-sectional differences in their returns. Following Ang et al. (2006a,b), we estimate Eq. (3) using monthly regression windows with daily data. In line with our previous results, we use the most commonly observed RVIX threshold level to identify low (high) expected volatility periods. More particularly, we identify months in which the threshold parameter RVIX is greater (less) than 9.33 as periods of high (low) uncertainty about expected aggregate volatility ${ }^{34}$. We denote corresponding betas as $\beta_{\mathrm{UNC}}$ and $\beta_{\mathrm{CALM}}$, respectively. The sample is the universe of CRSP stocks covering all

\footnotetext{
${ }^{34}$ We further tried six other threshold levels of RVIX ranging from 8.42 to 11.10 , which coincide with the next commonly observed RVIX threshold levels in our tests after 9.33. The results are robust to different threshold levels found in portfolio level analyses.
} 
NYSE/AMEX/NASDAQ common stocks with share codes 10 and 11 . The regressions are estimated each month from January 1986 to December 2010.

We next conduct portfolio-level analysis to investigate cross-sectional predictive power of $\beta_{\text {UNC }}$ and $\beta_{\text {CALM }}$ For each month, from February 1986 to December 2010, stocks are sorted into decile portfolios based on their $\beta_{\mathrm{UNC}}$ and $\beta_{\mathrm{CALM}}$. Our portfolio formation exercise uses information available only as of the formation date. Hence it avoids potential look-ahead bias in the estimation of betas. Decile 1 (10) contains stocks with the lowest (highest) betas. Next-month post-ranking portfolio returns are calculated using both equally- and value-weighted weighting schemes, and the procedure is repeated each month. Table 7 reports next-month returns, CAPM and Fama and French (1993) 3-factor alphas of $\beta_{\mathrm{UNC}}$ and $\beta_{\mathrm{CALM}}$.sorted deciles.

Univariate portfolio sorts indicate an almost monotone and negative relationship between the betas and next-month average returns when uncertainty about expected aggregate volatility is high. Portfolio of stocks with lowest $\beta_{\mathrm{UNC}}$ (portfolio 1) earns $1.72 \%$ per month, whereas return on the portfolio of stocks with highest $\beta_{\text {UNC }}$ (portfolio 10) is $1.16 \%$ per month. The spread portfolio which is long in the highest $\beta_{\text {UNC }}$ stocks and short in the lowest $\beta_{\text {UNC }}$ stocks $(10-1)$ loses on average $0.72 \%$ per month with a $t$-statistic of -2.92 . Next month's risk-adjusted returns (CAPM and FF 3-factor alphas) as well as value-weighted returns (both raw and risk-adjusted) also imply a negative beta next-month stock return relationship during periods of high uncertainty about expected aggregate volatility, with alphas and raw returns of the spread portfolio ranging from $-0.49 \%$ to $-0.73 \%$ with almost all but one being significant at $5 \%$ level.

On the other hand, our proposed model is able to establish a positive beta next-month stock return relationship during periods of low uncertainty about expected aggregate volatility. In particular, portfolio of stocks with lowest $\beta_{\text {CALM }}$ (portfolio 1) earns $1.84 \%$ per month, whereas return on the portfolio of stocks with highest $\beta_{\text {CALM }}$ (portfolio 10 ) is $2.44 \%$ per month. The spread portfolio which is long in the highest $\beta_{\text {CALM }}$ stocks and short in the lowest $\beta_{\text {CALM }}$ stocks earns on average $0.60 \%$ per month which is significant at $5 \%$ level. Although value-weighted returns further confirm a positive beta stock return relationship at periods of low uncertainty about aggregate volatility, next month's risk-adjusted returns (CAPM and FF 3-factor alphas) of the spread portfolio are relatively lower and insignificant. Overall, betas implied by the threshold level of RVIX capture uncertainty about expected aggregate volatility indicating that cross-section of expected returns are systematically related to the level of uncertainty about aggregate volatility.

\subsubsection{Fama-MacBeth (1973) tests for risk premia}

There is now a consensus on time variation in market risk. The conditional CAPM is an attempt to capture this variation. However, Ghysels (1998) shows that the conditional CAPM is unable to specify time variation accurately, leading to higher pricing errors compared to the unconditional CAPM. In view of these findings, we believe that it is crucial to understand the true dynamics of time variation in beta risk and incorporate this dynamics in the pricing model. Our previous findings establish that beta risk exhibits significant changes triggered by shifts in investors' expectations regarding the evolution of near-term aggregate volatility. Hence, the next natural step would be to analyze whether this risk is priced in the cross-section.

We employ standard Fama and MacBeth (1973) two-pass regression methodology. The full model to be tested is

$$
r_{i, t}^{j}=\alpha_{t}^{j}+\beta_{\mathrm{MKT}, i, t}^{j} \lambda_{\mathrm{MKT}, t}^{j}+\sum_{k=1}^{K} \beta_{k, i, t}^{j} \lambda_{k, t}^{k}+\varepsilon_{i, t}^{j}, \quad j=0,1,2
$$

where $\lambda$ 's represent unconditional prices of risk for various loadings and characteristics, and $j=0,1$, and 2 represent full sample, low and high uncertainty about expected volatility, respectively. In line with our previous results, we use the most commonly observed RVIX threshold level to identify low (high) uncertainty periods. More particularly, we identify months in which the threshold parameter RVIX is greater (less) than 9.33 as uncertain (calm) periods about expected aggregate volatility.

In the first pass, beta loadings are estimated at each month using daily observations. In the second pass, a cross-sectional regression is run each month, with beta loadings obtained from the first pass 
Table 7

Univariate portfolio sorts based on threshold RVIX betas.

\begin{tabular}{|c|c|c|c|c|c|c|c|c|c|c|c|}
\hline \multicolumn{12}{|c|}{ Panel A: portfolios based on $\beta_{\mathrm{UNC}}$} \\
\hline & 1 (low) & 2 & 3 & 4 & 5 & 6 & 7 & 8 & 9 & 10 (high) & $10-1$ \\
\hline \multicolumn{12}{|l|}{ Equally-weighted } \\
\hline Average return & $\mathbf{1 . 7 1 9}[3.31]$ & $1.243[3.10]$ & $1.328[3.54]$ & $1.232[3.39]$ & $1.204[3.32]$ & 1.175 [3.07] & $1.101[2.68]$ & $1.175[2.75]$ & $1.166[2.34]$ & 0.999 [1.61] & $-0.720[-2.92]$ \\
\hline CAPM Alpha & 1.675 [3.57] & 1.166 [3.27] & $1.256[3.68]$ & $1.143[3.46]$ & $1.094[3.23]$ & 1.068 [2.97] & $0.929[2.38]$ & 1.044 [2.57] & $1.069[2.23]$ & $0.945[1.54]$ & $-0.730[-2.33]$ \\
\hline FF 3-Factor Alpha & $1.629[3.58]$ & $1.116[3.27]$ & $1.225[3.71]$ & $1.144[3.48]$ & $1.108[3.24]$ & $1.078[3.01]$ & $0.956[2.44]$ & $1.083[2.64]$ & $1.140[2.36]$ & $1.018[1.67]$ & $-0.612[-2.03]$ \\
\hline \multicolumn{12}{|l|}{ Value-weighted } \\
\hline Avg. Return & $\mathbf{1 . 4 6 9}[2.97]$ & $1.175[3.06]$ & $1.245[3.51]$ & $1.160[3.40]$ & $1.144[3.35]$ & $1.110[3.05]$ & $1.057[2.69]$ & $1.116[2.71]$ & $1.071[2.22]$ & $0.855[1.42]$ & $-0.614[-2.48]$ \\
\hline CAPM Alpha & $1.405[3.15]$ & $1.084[3.14]$ & $1.174[3.62]$ & $1.071[3.41]$ & $1.020[3.18]$ & $0.994[2.86]$ & $0.885[2.33]$ & $0.976[2.45]$ & $0.969[2.05]$ & $0.788[1.31]$ & $-0.617[-1.96]$ \\
\hline FF 3-Factor Alpha & $1.366[3.14]$ & $1.043[3.14]$ & $1.154[3.64]$ & $1.078[3.44]$ & $1.040[3.21]$ & $1.009[2.89]$ & $0.920[2.40]$ & $1.020[2.52]$ & $1.045[2.20]$ & $0.876[1.46]$ & $-0.490[-1.63]$ \\
\hline \multicolumn{12}{|c|}{ Panel B: portfolios based on $\beta_{\text {CALM }}$} \\
\hline & 1 (low) & 2 & 3 & 4 & 5 & 6 & 7 & 8 & 9 & 10 (high) & $10-1$ \\
\hline \multicolumn{12}{|l|}{ Equally-weighted } \\
\hline Average Return & $1.843[3.11]$ & 1.910 [4.23] & $1.930[5.30]$ & $1.792[5.11]$ & 1.864 [5.79] & $1.845[6.03]$ & $1.905[6.35]$ & $1.991[6.31]$ & $2.010[5.89]$ & $2.441[5.31]$ & $0.598[2.15]$ \\
\hline CAPM Alpha & $1.712[2.60]$ & 1.758 [3.52] & $1.800[4.60]$ & 1.592 [4.29] & $1.730[5.14]$ & 1.726 [5.39] & 1.771 [5.97] & $1.893[6.10]$ & 1.868 [5.68] & $2.257[5.25]$ & $0.545[1.32]$ \\
\hline FF 3-Factor Alpha & $1.730[2.40]$ & $1.766[3.30]$ & $1.765[4.17]$ & $1.560[4.01]$ & $1.614[4.47]$ & $1.630[4.84]$ & $1.679[5.42]$ & $1.653[5.51]$ & $1.608[5.16]$ & 1.940 [4.29] & $0.210[0.53]$ \\
\hline \multicolumn{12}{|l|}{ Value-weighted } \\
\hline Avg. Return & $1.682[2.94]$ & $1.802[4.15]$ & 1.849 [5.29] & $1.731[5.21]$ & $1.781[5.90]$ & $1.771[6.22]$ & $1.803[6.45]$ & 1.882 [6.39] & 1.916 [5.87] & $2.173[5.00]$ & $0.491[1.78]$ \\
\hline CAPM Alpha & 1.559 [2.38] & $1.671[3.40]$ & 1.729 [4.52] & 1.554 [4.35] & 1.659 [5.16] & $1.653[5.53]$ & $1.680[6.00]$ & 1.795 [6.18] & $1.777[5.62]$ & 1.978 [4.85] & 0.419 [0.99] \\
\hline FF 3-Factor Alpha & $\mathbf{1 . 6 3 1}[2.30]$ & $1.701[3.25]$ & $1.717[4.14]$ & $1.553[4.10]$ & $1.579[4.54]$ & $1.597[5.04]$ & $1.619[5.48]$ & $1.604[5.56]$ & $1.550[5.12]$ & $1.700[3.92]$ & $0.068[0.17]$ \\
\hline
\end{tabular}

This table reports next-month equally- and value-weighted returns, next-month CAPM alpha, next-month Fama and French (1993) 3-factor alpha and post-ranking average betas of $\beta_{\mathrm{UNC}}$ and $\beta_{\mathrm{CALM}}$ sorted decile portfolios, where $\beta_{\mathrm{UNC}}$ corresponds to betas estimated in periods of high uncertainty about aggregate volatility (RVIX $>9.33$ ) and $\beta_{\text {CALM }}$ corresponds to betas estimated in periods of low uncertainty about aggregate volatility (RVIX <9.33). Decile 1 (10) contains stocks with the lowest (highest) betas. The test assets are all NYSE/AMEX/NASDAQ common stocks with share codes 10 and 11. The sample period is from January 1986 to December 2010 (300 months). 
Table 8

Fama-MacBeth risk premium estimates.

\begin{tabular}{|c|c|c|c|c|c|c|c|}
\hline & I & II & III & IV & V & VI & VII \\
\hline BETA & $0.14(0.68)$ & & & & & & \\
\hline BETA-CALM & & $0.41\left(2.17^{* *}\right)$ & & $0.51\left(2.06^{* *}\right)$ & & $0.77\left(3.03^{* * *}\right)$ & \\
\hline BETA-UNC & & & $-1.50\left(-1.87^{*}\right)$ & & $-1.00(-1.02)$ & & $-0.96(-1.10)$ \\
\hline SMBBeta & & & & $0.31\left(1.68^{*}\right)$ & $-0.43(-1.03)$ & $0.22(1.29)$ & $0.07(0.59)$ \\
\hline HMLBeta & & & & $0.00(0.03)$ & $-1.03\left(-2.04^{* *}\right)$ & $-0.09(-0.49)$ & $-0.22\left(-2.00^{* *}\right)$ \\
\hline MOMBeta & & & & $0.05(0.16)$ & $-0.66(-0.80)$ & $0.13(0.45)$ & $0.08(0.42)$ \\
\hline IDIOVOL & & & & & & $0.77\left(2.91^{* * *}\right)$ & $-1.83\left(-6.50^{* * *}\right)$ \\
\hline SIZE & & & & & & $-0.27\left(-5.37^{* * *}\right.$ & )$-0.19\left(-4.47^{* * *}\right)$ \\
\hline $\mathrm{B} / \mathrm{M}$ & & & & & & $0.43\left(8.14^{* * *}\right)$ & $0.27\left(4.44^{* * *}\right)$ \\
\hline MOM & & & & & & $0.07\left(5.26^{* * *}\right)$ & $0.14\left(9.64^{* * *}\right)$ \\
\hline CONST & $1.11\left(4.13^{* * *}\right)$ & $1.59\left(6.23^{* * *}\right)$ & $-1.81\left(-1.83^{*}\right)$ & $1.19\left(7.12^{* * *}\right)$ & $-2.18\left(-3.34^{* * *}\right)$ & $4.51\left(6.74^{* * *}\right)$ & $2.60\left(4.57^{* * *}\right)$ \\
\hline $\operatorname{Adj} R^{2}$ & 1.74 & 1.46 & 3.51 & 7.13 & 10.69 & 9.78 & 13.74 \\
\hline
\end{tabular}

This table reports the estimates for the average coefficients from cross-sectional Fama-MacBeth (1973) regressions, $r_{i, t}^{j}=\alpha_{t}^{j}+$ $\beta_{\mathrm{MKT}, i, t}^{j} \lambda_{\mathrm{MKT}, t}^{j}+\sum_{k=1}^{K} \beta_{k, i, t}^{j} \lambda_{k, t}^{k}+\varepsilon_{i, t}^{j}, \quad j=0,1,2$ where $\lambda$ 's represent unconditional prices of risk for various factor loadings and firm characteristics, and $j=0,1$, and 2 represent full sample, calm (low expected volatility) and volatile (high expected volatility) periods, respectively. We identify months in which RVIX is less (greater) than threshold level 9.33 as calm (volatile) episodes. The test assets are all NYSE/AMEX/NASDAQ common stocks with share codes 10 and 11 . The sample period is from January 1986 to December 2010 (300 months). Regime 1 (Regime 2) corresponds to months where aggregate volatility is below (above) the threshold parameter. SMB and HML are portfolio loadings on Fama and French (1993) factors and MOM is the portfolio loading on the Carhart (1997) momentum factor model, all of which are measured using monthly data from the end of month $t-36$ to the end of month $t$. IDIOVOL is the idiosyncratic volatility measured each month using daily data as in Ang et al. (2006a,b). SIZE and $\mathrm{B} / \mathrm{M}$ are the log of market capitalization and the book-to-market ratio observed at the end of month $t$, respectively. MOM is firm-level momentum calculated using the stock return from month $t-12$ to $t-2$. The numbers in parentheses are the Newey-West (1987) corrected $t$-statistics for each coefficient estimate. The term adjusted $R^{2}$ denotes the cross-sectional $R^{2}$ statistic adjusted for the degrees of freedom.

${ }^{* * *},{ }^{* *}$, and ${ }^{*}$ Denotes significance at $1 \%, 5 \%$ and $10 \%$ level, respectively.

regressions and additional firm characteristics. The associated estimates for the intercept term, $\alpha$, and the risk premia, $\lambda$ 's, are given by the average of those cross-sectional regression estimates. Table 8 summarizes the risk premium estimates of associated models.

We test 7 different specifications of Eq. (7). The first column represents the market model using the full sample. Consistent with earlier findings, CAPM fails to produce a positive and significant risk premium. The second column estimates the price of market risk in low volatility regime. One can see that, for months where RVIX is less than 9.33 (257 months) market risk premium is positive and significant, hence the proposed V-CAPM is successful in establishing a significant sign regarding the price of market risk in periods when market volatility is not expected to change significantly. Column 3 estimates the price of market risk in high volatility periods, which corresponds to 43 months in our sample estimation period. We document a negative and significant market risk premium when the market is expected to exhibit high volatility.

A negative and significant market risk premium might seem counter-intuitive at first, and at odds with theoretical predictions of CAPM and relevant risk-based asset pricing theories where investors should be compensated with a positive risk premium for holding risky assets such as the market portfolio. However, from an empirical point of view, average realized returns can be negative in narrowly defined periods in which the reward for taking risk does not materialize. For example, according to data compiled by Shiller (2015), equity risk premium has been negative around $75 \%$ of the time during the period starting with Nifty Fifty of the 1970s to the end of 2007 just before the crisis. Our explanation for the negative risk premium is flight to safety during episodes when uncertainty about expected aggregate volatility is high. For uncertainty averse investors, these episodes reflect increase in ambiguity of expected returns where it becomes extremely difficult to assess which direction the market will go. These episodes are characterized as periods of unknown unknowns as argued by Baltussen et al. (2015), i.e. periods when investors don't know what they don't know about expected market volatility. One natural implication to avoid this ambiguity would be to fly to safe heavens such as bonds, which provide payoffs that are more known and certain. A second order implication for the 
cross-section of stocks is that there will also be a flight to safety from small and value stocks to big and growth stock because small and value stocks have higher sensitivities to overall market risk during periods of increased uncertainty about expected aggregate volatility.

To see whether the above results are robust and to make sure the cross-sectional tests are not suffering from an omitted variables bias, we test the proposed V-CAPM in the presence of different factor loadings as well as several firm characteristics that have been documented as important in asset pricing literature. The estimation in specification IV includes market loading as well as SMB, HML, and MOM loadings, all estimated in monthly windows using daily data. We see that market risk premium is still significant and positive, confirming the robustness of a significant and positive market risk premium in calm months. Furthermore, column $\mathrm{V}$ shows that the significance of negative market risk premium disappears when SMB, HML, and MOM factors are included in high uncertainty regime estimations. Finally, columns VI and VII include three firm characteristics, which are idiosyncratic volatility, market capitalization and book-to-market ratio. Idiosyncratic volatility puzzle (the fact that stocks with low (high) idiosyncratic volatility earn higher (lower) returns) has received considerable interest since it has been first documented by Ang et al. (2006b). We would like to explore whether idiosyncratic volatility is a priced risk factor or not using the implications of our threshold V-CAPM and the threshold RVIX variable ${ }^{35}$. We further incorporate firm size and $\mathrm{B} / \mathrm{M}$ ratio as additional firm characteristics.

Column VI confirms our previous finding that market risk premium is positive and significant in the presence of further additional variables. Specification VII confirms a negative but insignificant market risk premium in high uncertainty regime. We further document that idiosyncratic risk is also priced in both regimes. More interestingly, we document a positive relationship between idiosyncratic risk and returns in calm periods when uncertainty about aggregate volatility expectations is low, and a negative relationship only in high expected uncertainty periods. Idiosyncratic volatility risk is priced positively as in Malkiel and Xu (2006) during periods when expected aggregate volatility does not change significantly. On the others side, the idiosyncratic volatility puzzle (stocks with high idiosyncratic risk earn lower returns) is shown to be a phenomenon that is pertinent to episodes where investors' expect significant uncertainty about near-term aggregate volatility. Our results offer a partial uncertainty-based explanation to the idiosyncratic volatility puzzle.

Overall, the proposed V-CAPM does a good job in establishing a positive risk-return relationship based on market risk. During low uncertainty months, the price of market risk is positive and significant, which confirms our hypothesis that investors' expectation about the evolution of uncertainty about near-term aggregate volatility is an important determinant of their risk-return tradeoff. Furthermore, during high uncertainty months, the price of market risk is negative and significant, but the significance of negative market risk premium disappears and is subsumed by the HML strategy and idiosyncratic volatility during those months. CAPM has been much criticized due to its failure in establishing a positive risk-return relationship and its silence regarding several anomalies. The pricing tests in this section confirm that CAPM is still alive but need to be modified by taking into account investors' expectations regarding uncertainty about near-term volatility, and the proposed threshold V-CAPM is a step in this direction. The findings also offer interesting insights regarding the idiosyncratic volatility puzzle.

\subsection{Alternative measures of volatility and further robustness tests}

One limitation of using RVIX as a conditioning variable is obviously its time span. The data regarding VIX index can be traced back to January 1986 . On the other hand, using statistical measures of volatility has the advantage of covering much longer time horizons. To test the sensitivity of our results to alternative measures of volatility, we repeat tests presented in previous sections using several historical,

\footnotetext{
35 We measure idiosyncratic volatility as outlined in Ang et al. (2006a,b). More particularly, first on a daily basis we estimate the

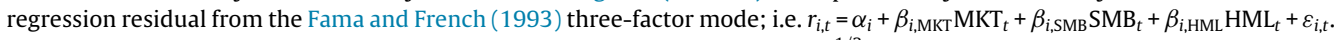
The idiosyncratic volatility is expressed as, $\operatorname{IDIOVOL}_{i, t}=\left((1 / T-1) \sum_{t=1}^{T} \varepsilon_{i, t}^{2}\right)^{1 / 2}$, where $T$ is the number of trading days within a calendar month.
} 
statistical and option-based measures as a proxy for aggregate volatility. These include the standard deviation of market returns, squared returns, monthly range of the market index (given by the maximum and minimum level of the market index in a given month), GARCH $(1,1)$ volatility, change in VIX index ( $\Delta$ VIX), and monthly returns on at-the-money straddles written on the S\&P 500 index. Neither of the four backward-looking statistical measures, nor the forward-looking option-based measure $(\Delta \mathrm{VIX})$ proved to yield significant results to model time variation in betas ${ }^{36}$.

On the other hand, monthly ATM S\&P 500 straddle returns produce very similar results to those obtained by range of the VIX index ${ }^{37}$. The results using monthly returns on ATM S\&P 500 straddles as the conditioning variable can be summarized as follows ${ }^{38}$. Similar to previous findings, most portfolios exhibit significant bootstrap $p$-values indicating a significant change in beta risk due to changes in returns on ATM straddles. Second, the direction of change in betas is very similar to results obtained using RVIX. We observe an increase in beta risk for small and value portfolios and a decrease in the risk of big and growth portfolios at times of high volatility, confirming our explanation that investors see small and value stocks much riskier in volatile market episodes, which usually coincides with deteriorations in investment opportunities and reductions in wealth.

We further examine Jensen's alphas, Sharpe ratios and the pricing performance of the proposed V-CAPM using ATM straddle returns as the conditioning variable and confirm that our volatility-based time-varying risk explanation to the observed size and value vs. growth anomalies is robust to the use of an alternative forward-looking market based volatility measure. Finally, looking at the crosssectional price of risk, using individual stock level data, we find that market risk is priced in the cross-section especially at times of low expected aggregate volatility, and is significantly positive.

\section{Conclusion}

We propose an asset pricing model where betas change discretely at different points in time. This change is due to investors' assessment of uncertainty about near-term aggregate volatility. Proxying investors' expectations regarding the uncertainty about near-term aggregate volatility with the range of the VIX index, RVIX, we document the following.

First we find that there exists significant time variation in market betas with respect to uncertainty in expected aggregate volatility. In particular, small market capitalization and value portfolios have consistently higher betas compared to big market capitalization and growth portfolios at times of high uncertainty about expected volatility. Moreover, the beta dispersions between small-big and valuegrowth portfolios are negative (positive) during calm (uncertain) periods about expected volatility. Because they correlate more with the market at times when investors expect significant uncertainty in aggregate volatility, small and value portfolios are viewed as riskier than big and growth portfolios in bad times when uncertainty about aggregate market volatility is expected to be high. This volatility-based risk explanation is further confirmed by the risk-adjusted returns implied by the VCAPM. During calm periods when uncertainty about expected aggregate volatility is low, small and value portfolios earn on average higher risk-adjusted returns than big and growth portfolios, however they become extremely risky strategies at times of increased uncertainty regarding expected volatility exhibiting negative and significant risk-adjusted returns. Finally, the proposed V-CAPM is able to establish a positive market risk premium during calm periods when uncertainty about expected aggregate volatility is low.

CAPM has been much criticized due to its failure in establishing a positive risk-return relationship and its silence regarding several pricing anomalies. There is now a consensus on time-variation in betas,

\footnotetext{
36 This confirms our argument that forward-looking volatility measures do a better job in capturing investors' expectations on aggregate market risk compared to statistical measures. The results also lend indirect support to Ang et al. (2006a,b) who find that statistical measures of aggregate volatility, such as sample volatility, extreme value volatility estimates, and realized volatility estimates, do not produce enough spread in the cross-section.

37 The significance of ATM straddle returns over $\Delta$ VIX supports Cremers, Halling, and Weinbaum (2015)who document that $\Delta$ VIX loses its significance in capturing volatility risk premium in the presence of measures constructed using ATM straddle returns.

${ }^{38}$ The results in detail related to ATM straddle returns are available upon request.
} 
but not on how this variation should be modelled. By using a novel forward looking option-implied volatility measure, we allow asset betas to incorporate information regarding investors' expectations about uncertainty in near-term aggregate volatility in a dynamic way. The proposed model and the related empirical results support the view of a risk-based rational asset pricing theory and offers a volatility-based explanation of risk-return dynamics where asset return sensitivities to market risk change discretely in time with respect to uncertainty in investors' expectations regarding near-term aggregate volatility.

\section{Acknowledgements}

We would like to thank to seminar participants and discussants at Grenoble Ecole de Management, Lancaster University Management School, Manchester Business School, SKEMA Business School, Université Paris Dauphine, Université Picardie Jules Verne, AFFI 2012 Strasbourg Meetings, and FMA 2012 Atlanta Meetings. The authors would also like to thank to the managing editor Hamid Beladi for a smooth editorial process and to two anonymous referees for their helpful suggestions and comments.

\section{References}

Alizadeh, S., Brandt, M., \& Diebold, F. (2002). Range-based estimation of stochastic volatility models. Journal of Finance, 57, 1047-1092.

Andersen, T. G. (1996). Return volatility and trading volume: An information flow interpretation of stochastic volatility. Journal of Finance, 51, 169-204.

Ang, A., \& Bekaert, G. (2002). International asset allocation with regime shifts. Review of Financial Studies, 15, 1137-1187.

Ang, A., \& Chen, J. (2002). Asymmetric correlations of equity portfolios. Journal of Financial Economics, 63, 443-494.

Ang, A., Chen, J., \& Xing, Y. (2006). Downside risk. Review of Financial Studies, 19, 1191-1239.

Ang, A., Hodrick, R. J., Xing, Y., \& Zhang, X. (2006). The cross section of volatility and expected returns. Journal of Finance, 61, 259-299.

Atilgan, Y., Bali, T., \& Demirtas, K. O. (2015). Implied volatility spreads and expected market returns. Journal of Business and Economic Statistics, 33, 87-101.

Bali, T., Demirtas, K. O., \& Levy, H. (2009). Is there an intertemporal relation between downside risk and expected returns? Journal of Financial and Quantitative Analysis, 44, 883-909.

Bali, T., \& Hovakimian, A. (2009). Volatility spreads and expected stock returns. Management Science, 55, 1797-1812.

Baltussen, G., Bekkum, S. V., \& Grient, B. V. D. (2015). Unknown unknowns: Uncertainty about risk and stock returns. Journal of Financial and Quantitative Analysis (forthcoming)

Bannouh, K., Martens, M., \& van Dijk, D. (2013). Forecasting volatility with the realized range in the presence of noise and non-trading. North American Journal of Economics and Finance, 26, 535-551.

Barinov, A. (2012). Aggregate volatility risk: Explaining the small growth anomaly and the new issues puzzle. Journal of Corporate Finance, 18, 763-781.

Bekaert, G., \& Wu, G. (2000). Asymmetric volatility and risk in equity markets. Review of Financial Studies, 13, 1-42.

Bianconi, M., MacLachlan, S., \& Sammon, M. (2015). Implied volatility and the risk-free rate of return in options markets. North American Journal of Economics and Finance, 31, 1-26.

Bollen, N. P., \& Whaley, R. E. (2009). Hedge fund risk dynamics: Implications for performance appraisal. Journal of Finance, 64, 987-1037.

Bollerslev, T., \& Mikkelsen, H. O. (1999). Long-term equity anticipation securities and stock market volatility dynamics. Journal of Econometrics, 92, 75-99.

Bollerslev, T., Tauchen, G., \& Zhou, H. (2009). Expected stock returns and variance risk premia. Review of Financial Studies, 22, 4463-4492.

Brandt, M., \& Jones, C. (2006). Volatility forecasting with range-based EGARCH models. Journal of Business and Economic Statistics, 79, 61-74.

Braun, P. A., Nelson, D. B., \& Sunier, A. M. (1995). Good news, bad news, volatility and betas. Journal of Finance, 50, $1575-1603$.

Buraschi, A., Porchia, P., \& Trojani, F. (2010). Correlation risk and optimal portfolio choice. Journal of Finance, 65, 393-420.

Buraschi, A., Trojani, F., \& Vedolin, A. (2014). When uncertainty blows in the orchard: Comovement and equilibrium volatility risk premia. Journal of Finance, 69, 101-137.

Busch, T., Christensen, B. J., \& Nielsen, M. O. (2011). The role of implied volatility in forecasting future realized volatility and jumps in foreign exchange, stock, and bond markets. Journal of Econometrics, 160, 48-57.

Campbell, J. Y. (1987). Stock returns and the term structure. Journal of Financial Economics, 18, 373-399.

Campbell, J. Y. (1993). Intertemporal asset pricing without consumption data. American Economic Review, 83, 487-512.

Campbell, J. Y., \& Hentschel, L. (1992). No news is good news: An asymmetric model of changing volatility in stock returns. Journal of Financial Economics, 31, 281-318.

Canina, L., \& Figlewski, S. (1993). The informational content of implied volatility. Review of Financial Studies, 6, 659-681.

Carhart, M. (1997). On peristence in mutual fund performance. Journal of Finance, 52, 57-82.

Chen, J. (2002). Intertemporal CAPM and the cross-section of stock returns. In Working paper. University of Southern California. 
Chen, C., Gerlach, R., \& Lin, A. (2011). Multi-regime nonlinear capital asset pricing models. Quantitative Finance, 11, 1421-1438.

Chou, R. Y. (2005). Forecasting financial volatilities with extreme values: The conditional autoregressive range (CARR) model. Journal of Money Credit and Banking, 37, 561-582.

Chou, R. Y., \& Liu, N. (2010). The economic value of volatility timing using a range-based volatility model. Journal of Economic Dynamics and Control, 34, 2288-2301.

Cremers, M., \& Weinbaum, D. (2010). Deviations from put-call parity and stock return predictability. Journal of Financial and Quantitative Analysis, 45, 335-367.

Cremers, M., Halling, M., \& Weinbaum, D. (2015). Aggregate jump and volatility risk in the cross-section of stock returns. Journal of Finance, 70, 577-614.

Duffee, G. R. (1995). Stock returns and volatility: A firm-level analysis. Journal of Financial Economics, 37, 399-420.

Engle, R. F., \& Bollerslev, T. (1986). Modelling the persistence of conditional variances. Econometric Reviews, 5, 1-50.

Engle, R. F., \& Ng, V. K. (1993). Measuring and testing the impact of news on volatility. Journal of Finance, 48, 1749-1778.

Fama, E. F., \& French, K. R. (1988). Dividend yields and expected stock returns. Journal of Financial Economics, 22, 3-25.

Fama, E. F., \& MacBeth, J. D. (1973). Risk, return, and equilibrium: Empirical tests. Journal of Political Economy, 81, $607-636$.

Fama, E. F., \& French, K. R. (1993). Common risk factors in the returns on stocks and bonds. Journal of Financial Economics, 33, 3-56.

Fama, E. F., \& Schwert, G. W. (1977). Asset returns and inflation. Journal of Financial Economics, 5, 115-146.

Ferson, W. E., \& Harvey, C. R. (1991). The variation of economic risk premiums. Journal of Political Economy, 99, 385-415.

Ferson, W. E., \& Korajczyk, R. A. (1995). Do arbitrage pricing models explain the predictability of stock returns? Journal of Business, 68, 309-349.

Ferson, W. E., \& Harvey, C. R. (1999). Conditioning variables and the cross section of stock returns. Journal of Finance, 54, 1325-1360.

French, K., Schwert, G. W., \& Stambaugh, R. F. (1987). Expected stock returns and volatility. Journal of Financial Economics, 19, $3-29$.

Garman, M. B., \& Klass, M. J. (1980). On the estimation of security price volatilities from historical data. Journal of Business, 53 , 67-78.

Ghysels, E. (1998). On stable factor structures in the pricing of risk: Do time varying betas help or hurt? Journal of Finance, 53 , 549-573.

Guidolin, M., \& Timmermann, A. (2008). Size and value anomalies under regime shifts. Journal of Financial Econometrics, 6, $1-48$.

Hamilton, J. D. (1989). A new approach to the economic analysis of nonstationary time series and the business cycle. Econometrica, 57, 357-384.

Hamilton, J. D., \& Lin, G. (1996). Stock market volatility and the business cycle. Journal of Applied Econometrics, 11, $573-593$.

Han, H., \& Park, M. D. (2013). Comparison of realized measure and implied volatility in forecasting volatility. Journal of Forecasting, 32, 522-533.

Hansen, B. E. (1996). Inference when a nuisance parameter is not identified under the null hypothesis. Econometrica, 64, $413-430$

Hansen, B. E. (2000). Sample splitting and threshold estimation. Econometrica, 68, 575-605.

Harris, R. D., Stoja, E., \& Yilmaz, F. (2011). A cyclical model of exchange rate volatility. Journal of Banking and Finance, 35 , 3055-3064.

Harvey, C. R. (1989). Time-varying conditional covariances in tests of asset pricing models. Journal of Financial Economics;, 24, 289-317.

Hsu, J., \& Li, F. (2009). Cyclicality in stock market volatility and optimal portfolio allocation. In G. N. Gregoriou (Ed.), Stock market volatility (pp. 195-207). Boca Raton, FL: Chapman \& Hall.

Jagannathan, R., \& Wang, Z. (1996). The conditional CAPM and the cross-section of expected returns. Journal of Finance, 51, 3-53.

Keim, D. B., \& Stambaugh, R. F. (1986). Predicting returns in the stock and bond markets. Journal of Financial Economics, 17, 357-390.

Lettau, M., \& Ludvigson, S. (2001). Resurrecting the (C)CAPM: A cross-sectional test when risk premia are time-varying. Journal of Political Economy, 109, 1238-1287.

Malkiel, B., \& Xu, Y. (2006). Idiosyncratic risk and security returns. In Working paper. University of Texas at Dallas.

Parkinson, M. (1980). The extreme value method for estimating the variance of the rate of return. Journal of Business, 53, 61-65.

Patten, A., \& Ramadorai, T. (2013). On the high-frequency dynamics of hedge fund risk exposures. Journal of Finance, 68, 597-635.

Petkova, R., \& Zhang, L. (2005). Is value riskier than growth? Journal of Financial Economics, 78, 187-202.

Pollet, J. M., \& Wilson, M. (2010). Average correlation and stock market returns. Journal of Financial Economics, 96, $364-380$.

Poon, S., \& Granger, C. (2005). Practical issues in forecasting volatility. Financial Analysts Journal, 61, 45-56.

Schwert, W. G. (1989). Why does stock market volatility change over time? Journal of Finance, 44, 1115-1153.

Sharpe, W. F. (1966). Mutual fund performance. Journal of Business, 39, 119-138.

Sharpe, W. F. (1975). Adjusting for risk in portfolio performance measurement. Journal of Portfolio Management, 1, 29-34.

Shiller, R. J. (2015). Irrational exuberance (3rd ed). Princeton, NJ: Princeton University Press.

Taylor, S. J., Yadav, P. K., \& Zhang, Y. (2010). The information content of implied volatilities and model-free volatility expectations: evidence from options written on individual stocks. Journal of Banking and Finance, 34, 871-881.

Wang, Y., \& Ma, J. (2014). Excess volatility and the cross-section of stock returns. North American Journal of Economics and Finance, 27, 1-16.

Welch, I., \& Goyal, A. (2008). A comprehensive look at the empirical performance of equity premium prediction. Review of Financial Studies, 21, 1455-1508. 